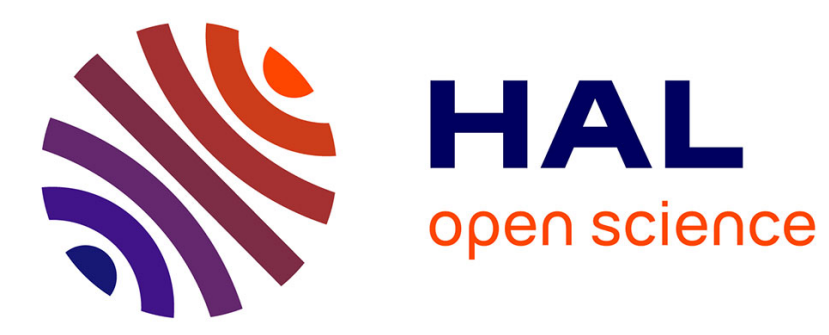

\title{
The reference point in dynamic Prospect-based User Equilibrium: a simulation study
}

\author{
Sergio Batista, Ludovic Leclercq
}

\section{To cite this version:}

Sergio Batista, Ludovic Leclercq. The reference point in dynamic Prospect-based User Equilibrium: a simulation study. Transportation Letters, 2020, 12 (8), pp513-527. hal-02497334v3

\section{HAL Id: hal-02497334 \\ https://hal.science/hal-02497334v3}

Submitted on 13 Jan 2021

HAL is a multi-disciplinary open access archive for the deposit and dissemination of scientific research documents, whether they are published or not. The documents may come from teaching and research institutions in France or abroad, or from public or private research centers.
L'archive ouverte pluridisciplinaire HAL, est destinée au dépôt et à la diffusion de documents scientifiques de niveau recherche, publiés ou non, émanant des établissements d'enseignement et de recherche français ou étrangers, des laboratoires publics ou privés. 


\title{
The reference point in dynamic Prospect-based User Equilibrium: a simulation study
}

\author{
S. F. A. Batista ${ }^{\mathrm{a}, *}$, Ludovic Leclercq ${ }^{\mathrm{a}}$ \\ ${ }^{a}$ Univ. Lyon, ENTPE, IFSTTAR, LICIT, F-69518, Lyon, France
}

\begin{abstract}
In this paper, we revisit the concept of Prospect-based User Equilibrium and extend it to dynamic traffic assignment. We propose a solution algorithm to calculate the network equilibrium that is based on the Method of Successive Averages. Monte Carlo simulations are considered to account for the distributions of route travel times. A mesoscopic Lighthill-Whitham-Richards (LWR) traffic model is used to determine time-dependent route costs that account for congestion and spillback effects. We analyze the dynamic Prospect-based User Equilibrium compared to the benchmarks DUE and SUE, on a synthetic Manhattan traffic network. We consider four endogenous settings of the reference point. We show that these settings play a very important role in the route flow patterns and on the network performance at an aggregated level, in terms of vehicles mean speed as well as internal and outflow capacities. We show that the Prospect-based User Equilibrium is more sensitive to a change in the reference point setting than in the calibration of the users' risk-aversion and risk-seeking parameters.
\end{abstract}

Keywords: Risk-seeking and risk-aversion users' behavior, Prospect theory, Dynamic traffic assignment, Network performance, LWR traffic model.

\section{Highlights}

- We enhance the importance of the reference point in the application of Prospect Theory to route choice.

- We investigate the influence of users risk-seeking and risk-aversion behavior in the traffic network performance.

- We propose the first implementation of Prospect Theory in a dynamic context, where travel costs are determined by a LWR traffic model.

- We propose a solution algorithm to calculate the dynamic Prospect-based User Equilibrium.

- We show that the concepts of disutility minimization and prospect maximization give different route flow patterns, depending on the reference point.

\section{Introduction}

The concept of Dynamic Traffic Assignment (DTA) was introduced by the seminal works of Merchant and Nemhauser (1978a) and Merchant and Nemhauser (1978b). Up to now, most of the DTA applications discussed in the literature are based on the Deterministic User Equilibrium (DUE) (Wardrop, 1952) and Stochastic User Equilibrium (SUE) (Daganzo and Sheffi, 1977; Daganzo, 1982). The DUE assumes that users are fully informed about the travel times for their trips and they seek to minimize their own travel times (Wardrop, 1952). The SUE assumes that travel times have an uncertainty associated due to changes in traffic conditions over time. The modeling of the SUE is

\footnotetext{
${ }^{*}$ Corresponding author. Tel. : +33 (0) 472047165

Email address: sergio.batista@ifsttar.fr (S. F. A. Batista)
} 
based on the application of different Random Utility models (McFadden, 1978; Prato, 2009), depending on which assumptions are made on the perception error. Revealed (Zhu, 2011) and stated (Avineri and Prashker, 2004) preference surveys show that users do not always aim to minimize their own travel times. Therefore, both the DUE and SUE have an inherent strong users' behavior assumption. In the literature of traffic assignment, there are other alternative models that take into account more realistic users' behavior. The latter includes bounded rational users (Simon, 1957; Mahmassani and Chang, 1987; Huang and Lam, 2002; Szeto and Lo, 2006; Batista et al., 2018), regret-averse users (e.g. Chorus, 2014; Li and Huang, 2016) and users risk preferences (e.g. Bates et al., 2000; Avineri, 2006; Shao et al., 2006; Chen and Zhou, 2010). But, few efforts have been made to adapt these models to DTA problems.

In this paper, we focus on the users' choices over alternatives that involve risk. In many studies in the literature, the users' risk preferences have been associated to the reliability of travel times, i.e. the variance of the travel times distributions. In this case, users have a preference for more reliable travel times. Several modeling approaches have been discussed in the literature: the mean-variance model (Jackson and Jucker, 1982); the scheduling-delay (Small, 1982; Watling, 2006); the travel time budget (Shao et al., 2006; Shao et al., 2006; Lo et al., 2006; Lam et al., 2008); the mean-excess traffic model (Chen and Zhou, 2010; Chen et al., 2011); and the added-variability model (Ordóñez and Stier-Moses, 2010), to name a few examples. Bell (2000) and Bell and Cassir (2002) propose a non-cooperative game, where users are pessimistic about their travel times variability and show a risk-aversion behavior. Nevertheless, Katsikopoulos et al. (2000) conducted a stated preferences survey and participants showed to be risk-averse when the travel time of a route is below a certain threshold travel time and risk-seeking in the opposite scenario. In this spirit, the application of Prospect Theory (Kahneman and Tversky, 1979; Tversky and Kahneman, 1992) seems to be more appealing. It is a behavioral economic theory. The outcomes of the possible choices are framed as prospects, that are evaluated as gains and losses against a reference point, i.e. status quo. Users evaluate the gains and losses differently. In fact, people are more sensible to a loss than an equivalent amount of gain. As an example, we feel a greater emotional impact on a loss of 50\$ than on a similar amount of gain, i.e. the loss effect. In Prospect Theory, users want to maximize their gains. Users are also risk-averse when confronted with prospects of gains and risk-seeking when confronted with prospects of losses. In the traffic community, Prospect Theory has been applied by many studies to model users' choices for their departure time (Fujii and Kitamura, 2004; Jou et al., 2008), routes (Avineri and Prashker, 2004; Viti et al., 2005; Avineri, 2006; Connors and Sumalee, 2009; Sumalee et al., 2009; Gao et al., 2010; Ramos et al., 2011; Xu et al., 2011; Ramos et al., 2013) or bus lines (Avineri, 2004).

The concept of Prospect-based User Equilibrium was first established by Avineri (2006) for stochastic traffic networks. This concept was generalized by Connors and Sumalee (2009), where the mathematical formulation was introduced. Sumalee et al. (2009) further extended this definition of the network equilibrium to account for endogenous stochastic demands and supply. But, the application of Prospect Theory to traffic assignment strongly relies on the choice of the reference point, as evidenced by Avineri (2006). The applications of Prospect Theory presented by Avineri (2006), Connors and Sumalee (2009) and Sumalee et al. (2009) rely on exogenously defined reference points. $\mathrm{Xu}$ et al. (2011) extended the Prospect-based User Equilibrium to consider endogenous reference point, for stochastic traffic networks. While several studies discussed the implementation of Prospect Theory to traffic assignment, there are several questions that still remain to be explored. First, the application of Prospect Theory has only been based on static implementations and small networks. Connors and Sumalee (2009) investigated the implementation of Prospect Theory on a static traffic assignment context on a 2 links network and on a Braess network. Xu et al. (2011) also considered a static implementation of Prospect Theory on a 4 links network as well as on the Nguyen and Dupui's network. Up to our best knowledge, there is still no study that investigates the implementation of Prospect Theory in a dynamic context, i.e. where travel times are time-dependent and account for spill-back and shock-wave effects. Second, travel times are not deterministic due to changes of traffic conditions over time. On the contrary, time prospects are deterministic. Only Sumalee et al. (2009), Xu et al. (2011) and Yang and Jiang (2014) discuss the application of Prospect Theory for stochastic traffic network and static traffic assignment problems. Third, the setting of the reference point is a key ingredient in the application of Prospect Theory. Particularly, in the case of traffic assignment problems, the setting of the reference point is yet not consensual (Avineri, 2006; de Palma et al., 2008; Avineri and Bovy, 2008; Connors and Sumalee, 2009; Gao et al., 2010; Zhou et al., 2014). In this paper, we propose the first implementation of Prospect Theory to a DTA problem, considering travel times uncertainties. We calculate time-dependent route travel times that account for congestion and spill-back effects, through a LighthillWhitham-Richards (LWR) mesoscopic traffic simulator (Leclercq and Becarie, 2012). The goal of this paper is not to propose a new paradigm for the setting of the reference point, we investigate its influence in the application of 
Prospect Theory to traffic assignment. We revisit the concept of Prospect-based User Equilibrium, to investigate the influence of the users' risk-seeking and risk-aversion behavior on the traffic network mean speed as well as internal and outflow capacities. We analyze the traffic network performance against the classical DUE and SUE models. For these tests, we consider a synthetic Manhattan traffic network.

This paper is organized as follows. In Sect. 2, we introduce the theoretical formulation of Prospect Theory and review the key points for its application. In Sect. 3, we discuss the mathematical formulation of the Prospect-based User Equilibrium and present a solution algorithm. In this paper, the dynamic traffic assignment framework is based on a quasi-static approximation. We then analyze how the algorithm converges in a simple static assignment problem on a 3 road network. In Sect. 4, we investigate the influence of the users' risk-seeking and risk-aversion behavior on the performance of a synthetic Manhattan traffic network, compared to the benchmarks DUE and SUE. In Sect. 5, we outline the conclusions.

\section{Prospect Theory: theoretical background and key points}

Kahneman and Tversky (1979) and Tversky and Kahneman (1992) introduced Prospect Theory to model users' choices over alternatives of which the outcomes involve risk. By other words, the outcome of each alternative has a given probability to happen and is evaluated as a prospect of gain or loss compared to a reference point. In this paper, we focus our attention on the application of Prospect Theory to traffic assignment. Therefore, the question is how to model users' decisions about the time prospects. In Sect. 2.1, we introduce the mathematical background of Prospect Theory. We then dissect the two fundamental points for the application of Prospect Theory. In Sect. 2.2, we discuss the setting of the reference point in the traffic assignment context. In Sect. 2.3, we discuss the calibration of the parameters that determine how users differently evaluate gains and losses as well as how they weight the probabilities associated to each outcome.

In Table 1 we summarize the notations of all symbols and variables used in this paper.

Table 1: Nomenclature used in this paper.

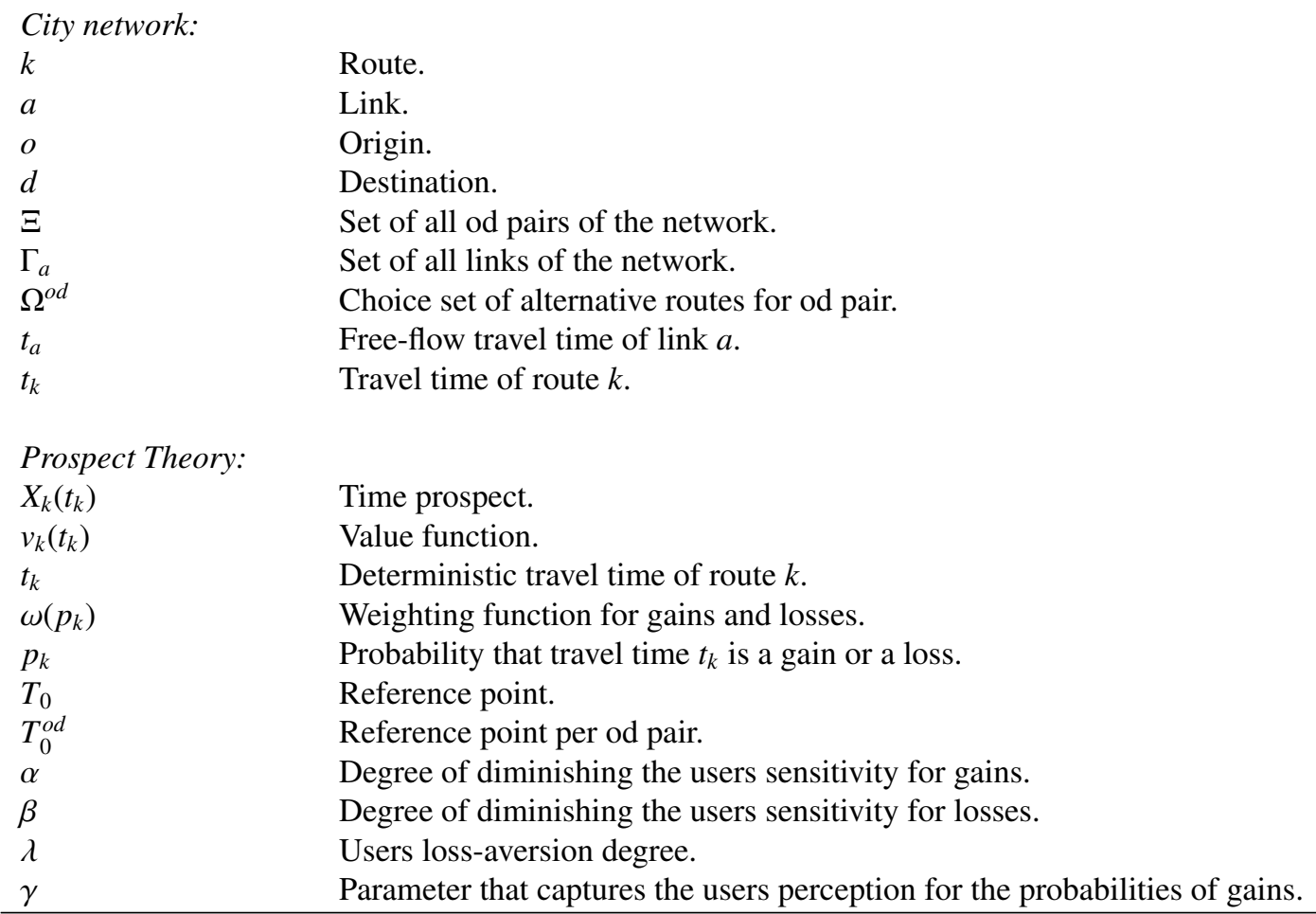


Table 1 - Continued from previous page

\begin{tabular}{|c|c|}
\hline$\phi$ & Parameter that captures the users perception for the probabilities of losses. \\
\hline$\vec{V}^{\text {od }}$ & $\begin{array}{l}\text { Vector that contains the mean values of the route travel times distributions for the od } \\
\text { pair. }\end{array}$ \\
\hline$\delta^{o d}$ & Acceptability risk tolerance band for the od pair. \\
\hline \multicolumn{2}{|c|}{ Prospect-based User } \\
\hline \multicolumn{2}{|c|}{ Equilibrium: } \\
\hline$Q^{o d}$ & Total demand for the od pair. \\
\hline$Q_{k}^{o d}$ & Flow of route $k$ of the od pair. \\
\hline$q_{a}$ & Flow of link $a$. \\
\hline$T_{k}$ & Perceived route utility. \\
\hline$Z_{k}$ & Deterministic route utility. \\
\hline$\epsilon_{k}$ & Route uncertainty or error term. \\
\hline$\epsilon_{a}$ & Link error or uncertainty term. \\
\hline$\delta_{a k}$ & Dummy variable that equals 1 if link $a$ belongs to route $k$. \\
\hline$M$ & Number of samples for the error term discretization. \\
\hline$\eta_{a}$ and $\zeta_{a}$ & Scale and shape parameters of a gamma distribution. \\
\hline$t_{a}^{i}$ & Sample $i$ of the travel time distribution of link $a$. \\
\hline$t_{k}^{i}$ & Sample $i$ of the travel time distribution of route $k$. \\
\hline$\delta_{a k}$ & Binary variable that equals 1 if route $k$ travels on link $a$, or 0 otherwise. \\
\hline \multicolumn{2}{|c|}{ Method of Successive } \\
\hline \multicolumn{2}{|c|}{ Averages: } \\
\hline$j$ & Iteration $j$ of the Method of Successive Averages. \\
\hline$\tau_{j}$ & Descent step of the Method of Successive Averages. \\
\hline$Q_{k}^{O D, j+1}$ & Flow of route $k$ at iteration $j+1$. \\
\hline$Q_{k}^{\delta D, j}$ & Flow of route $k$ at iteration $j$. \\
\hline$Q_{k}^{O D, *}$ & New temporary flow of route $k$. \\
\hline$N(\lambda)$ & Number of violations. \\
\hline$\Phi$ & Pre-defined threshold for the number of violations. \\
\hline$N_{\max }$ & Maximum number of descent step iterations. \\
\hline$T$ & Simulation period. \\
\hline$d t$ & Assignment period. \\
\hline Gap & Relative gap. \\
\hline$R M S E$ & Root mean square error. \\
\hline \multicolumn{2}{|c|}{ Other variables: } \\
\hline$\vec{Q}$ & Vector that contains the all route flows for the od pair. \\
\hline$u$ & Free-flow speed. \\
\hline$w$ & Wave speed. \\
\hline$k_{\text {jam }}$ & Jam density. \\
\hline
\end{tabular}

\subsection{Prospect Theory: basic formulation}

In the context of traffic assignment, users frame travel times as time prospects. During the first editing phase, time prospects are framed as gains and losses against a reference point $T_{0}$. Then, during an evaluation phase, users choose the maximum time prospect that is perceived. 
The time prospect $X_{k}\left(t_{k}\right)$ of route $k$ is:

$$
X_{k}\left(t_{k}\right)=v_{k}\left(t_{k}\right) \omega\left(p_{k}\right), \forall k \in \Omega^{o d} \wedge \forall(o, d) \in \Xi
$$

where $v_{k}\left(t_{k}\right)$ is the value function and $t_{k}$ is the deterministic travel time of route $k ; \omega\left(p_{k}\right)$ is the weighting function for gains and losses; $p_{k}$ is the probability that the perceived travel time of route $k$ is a gain or a loss; $\Omega^{\text {od }}$ is the route choice set; and $\Xi$ is the set of all od pairs of the city network.

The value function $v_{k}\left(t_{k}\right)$ (Kahneman and Tversky, 1979; Tversky and Kahneman, 1992) determine how users value the gains and losses against the reference point $T_{0}$. It is defined as:

$$
v_{k}\left(t_{k}\right)= \begin{cases}\left(T_{0}-t_{k}\right)^{\alpha}, & \text { if } t_{k} \leq T_{0} \\ -\lambda\left(t_{k}-T_{0}\right)^{\beta}, & \text { if } t_{k}>T_{0}\end{cases}
$$

where $T_{0}$ is the reference point; $\alpha \leq 1$ and $\beta \leq 1$ represent the degrees of diminishing sensitivity for gains and losses, respectively; and $\lambda \geq 1$ is the loss-aversion degree. The parameters $\alpha$ and $\beta$ control the concavity and convexity of $v_{k}\left(t_{k}\right)$. Note that if $\alpha=\beta=1$ users are pure loss averse. In Fig. 1, we show the shape of $v_{k}\left(t_{k}\right)$. As one can observe, users joy increase with the increase of gains. Whilst, users feel more emotional pain as the losses increase.

The weighting function $\omega(p)$ (Kahneman and Tversky, 1979; Tversky and Kahneman, 1992) determines how users deal with the outcome probabilities. It is defined as:

$$
\omega\left(p_{k}\right)= \begin{cases}\frac{p_{k}^{\gamma}}{\left(p_{k}^{\gamma}+\left(1-p_{k}\right)^{\gamma}\right)^{\frac{1}{\gamma}}}, & \text { if } t_{k} \leq T_{0} \\ \frac{p_{k}^{\delta}}{\left(p_{k}^{\delta}+\left(1-p_{k}\right)^{\delta}\right)^{\frac{1}{\delta}}}, & \text { if } t_{k}>T_{0}\end{cases}
$$

where $\gamma>0$ and $\delta>0$ capture the distortion in the perception of the probability $p_{k}$ for gains or losses, respectively. These parameters also control the curvature of $\omega\left(p_{k}\right)$ (see Eq. 3). This definition of $\omega\left(p_{k}\right)$ has some important properties: (i) $w(0)=0$; (ii) $w(1)=1$; (iii) is asymmetrical with an inflection point at 0.3 (Prelec, 1998); and (iv) it overweights small probabilities and underweights higher ones. In Fig. 1, we show the shape of $\omega\left(p_{k}\right)$.

For the application of Prospect Theory, there are two fundamental points that need to be properly calibrated: (i) the reference point $T_{0}$; and (ii) the sets of $(\alpha, \beta, \lambda)$ parameters of the value function and $(\gamma, \phi)$ parameters of the weighting function. This is described in more detail in the next two sections.

\subsection{The reference point $T_{0}$}

The setting of the reference point $T_{0}$ for the Prospect Theory application to traffic assignment problems has not been consensual in the literature (de Palma et al., 2008). It is still a research question in traffic assignment problems. Avineri (2006), Connors and Sumalee (2009) and Sumalee et al. (2009) considered an exogenous definition of $T_{0}$. These studies show that the setting of $T_{0}$ strongly influences the route flow patterns in the traffic network. Other authors propose to calibrate the reference point $T_{0}$ based on empirical surveys (see e.g. Senbil and Kitamura, 2004; Jou et al., 2008; Ceder et al., 2013; Zhou et al., 2014). For DTA applications, an endogenous definition of the reference point is more appropriate. Avineri and Bovy (2008) proposed to consider the mean or median of the route travel times. Gao et al. (2010) discusses some insights to set $T_{0}$ as a latent variable and to calculate it based on the free-flow travel time, the worst travel time or the mean of the travel times. Ben-Elia and Shiftan (2010) and Kemel and Paraschiv (2013) also consider the mean of the travel times. Xu et al. (2011) considers a time budget reference point. Zhou et al. (2014) considered the average travel times calculated from the route travel time distributions of the different alternatives. Jiang et al. (2014) set the reference point as the average of the free-flow travel times of the alternative routes.

In this paper, we assume a common reference point $T_{0}$ for all users sharing the same od pair (that is $T_{0}^{o d}$ ). We focus on three endogenous definitions discussed in the literature:

$$
T_{0}^{o d}=\operatorname{mean}\left(\vec{V}^{o d}\right)
$$



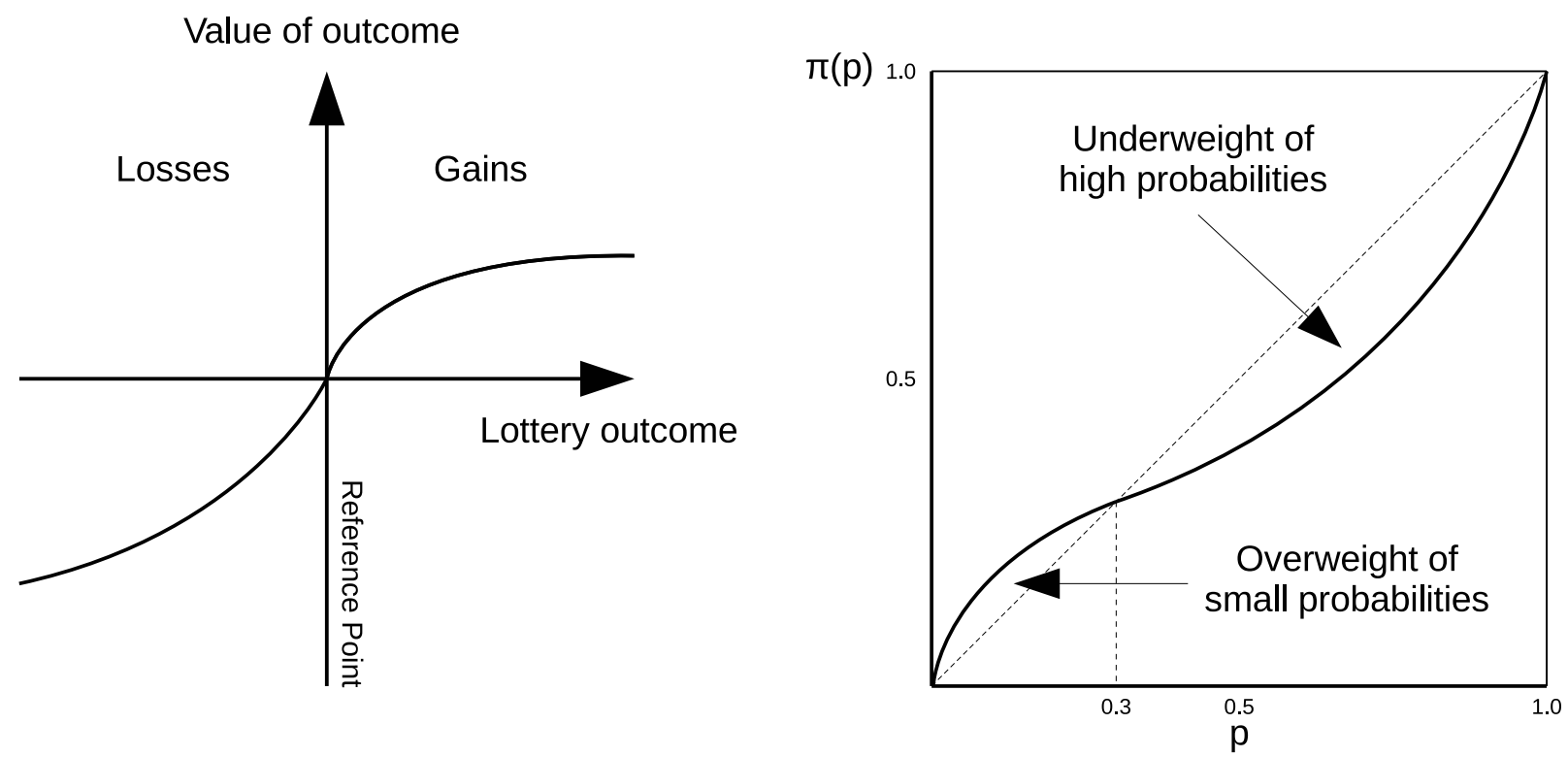

Figure 1: Left: Value function $v_{k}\left(t_{k}\right)$. Right: Probability weighting function $\omega\left(p_{k}\right)$. These functions are defined by Kahneman and Tversky (1979) and Tversky and Kahneman (1992).

$$
\begin{aligned}
& T_{0}^{o d}=\operatorname{median}\left(\vec{V}^{\text {od }}\right) \\
& T_{0}^{o d}=\operatorname{mode}\left(\vec{V}^{\text {od }}\right)
\end{aligned}
$$

where $\vec{V}^{\text {od }}$ is a vector that contains the mean values of the route travel times distributions for the od pair.

We also propose a different endogenous definition of $T_{0}^{o d}$, that is based on an acceptability risk tolerance band $\delta^{o d}$ for the desired travel time. It is defined as:

$$
T_{0}^{o d}=\left(1+\delta^{o d}\right) \min \left(\vec{V}^{o d}\right)
$$

where the acceptability tolerance band $\delta^{o d} \in\left[0,+\infty\left[\right.\right.$. Note that, when $\delta^{o d}$, users are strict on their travel times. Whilst, when $\delta^{o d}$ is large, users are more relaxed about their travel times. For example, a small $\delta^{o d}$ value might represent people that want to go to work and a large $\delta^{o d}$ value might represent people that will go to do some leisure activity and are more relaxed about their travel times.

\subsection{The users' risk-aversion parameters}

Another important ingredient for the application of Prospect Theory is the calibration of the sets $(\alpha, \beta, \lambda)$ and $(\gamma, \phi)$ for the value and weighting functions, respectively. These parameters are context dependent and may vary from user to user. Avineri and Bovy (2008) investigated the calibration of these parameters in the traffic assignment context. As an example, Avineri and Bovy (2008) shows that the loss-aversion degree $\lambda$ varies across the period of the day. The authors calculate that $\lambda=0.76$ for the morning peak and $\lambda=1.62$ for the afternoon peak. The off peak value is $\lambda=1.28$. Up to our best knowledge, only the set of parameters used by Xu et al. (2011) has been calibrated in a traffic assignment context: $(\alpha, \beta, \lambda, \gamma, \phi)=(0.37,0.57,1.51,0.74,0.74)$. Several other studies (see e.g. Yang and Jiang, 2014) used the set of parameters proposed by Tversky and Kahneman (1992): $(\alpha, \beta, \lambda, \gamma, \phi)=(0.88,0.88,2.25,0.61,0.69)$. Nevertheless, this set of parameters were not calibrated in a traffic assignment experiment and one should be careful in drawing conclusions when considering it. 


\section{Prospect Theory Stochastic User Equilibrium}

\subsection{Prospect-based User Equilibrium and solution algorithm}

In this paper, we follow the mathematical formulation of the Prospect-based User Equilibrium proposed by Connors and Sumalee (2009) and Xu et al. (2011). In Prospect Theory, users aim to maximize their travel time prospect $X_{k}\left(t_{k}\right), \forall k \in \Omega^{o d} \wedge \forall(o, d) \in \Xi$. Therefore, under Prospect-based User Equilibrium, the time prospects of all used routes are equal to the maximum time prospect value for each od pair. Moreover, under equilibrium conditions, no user can increase his or her own time prospect $X_{k}\left(t_{k}\right)$ by unilaterally changing routes. This definition of equilibrium was introduced by Avineri (2006). Mathematically, the Prospect-based User Equilibrium can be described as (Connors and Sumalee, 2009; Xu et al., 2011):

$$
\begin{aligned}
& Q_{k}^{\text {od }}\left(\max \left(X_{k}^{\text {od }}\left(t_{k}^{\text {od }}\right)\right)-X_{k}^{\text {od }}\left(t_{k}^{\text {od }}\right)\right)=0, \forall k \in \Omega^{\text {od }} \wedge \forall(o, d) \in \Xi \\
& \left\{\begin{array}{l}
Q_{k}^{\text {od }}>0, \quad \text { if } X_{k}^{\text {od }}\left(t_{k}^{\text {od }}\right)=\max \left(X_{k}^{\text {od }}\left(t_{k}^{\text {od }}\right)\right) \\
Q_{k}^{\text {od }}=0, \quad \text { if } X_{k}^{\text {od }}\left(t_{k}^{\text {od }}\right) \leq \max \left(X_{k}^{\text {od }}\left(t_{k}^{\text {od }}\right)\right)
\end{array}\right. \\
& \sum_{k} Q_{k}^{\text {od }}=Q^{\text {od }}, \forall(o, d) \in \Xi \\
& q_{a} \geq 0, \forall a \in \Gamma_{a} \\
& Q_{k}^{\text {od }} \geq 0, \forall k \in \Omega^{\text {od }} \wedge \forall(o, d) \in \Xi
\end{aligned}
$$

where $Q_{k}^{o d}$ is the flow of route $k$ of the od pair; $q_{a}$ is the flow of link $a ; \Gamma_{a}$ is the set of links of the graph that represents the traffic network; and $Q^{\text {od }}$ is the total demand for the od pair.

We make use of the Method of Successive Averages (or MSA) to determine the Prospect-based User Equilibrium defined by the system of equations Eq. 8 to Eq. 12. The travel times at the link level are assumed to be gamma distributed (Nielsen, 1997), with scale parameter $\eta_{a}$ and shape parameter $\zeta_{a}$. Monte Carlo simulations (Sheffi, 1985) are used to account for the travel times uncertainties. The idea is to discretize the link travel times into $M$ samples. Let $t_{a}^{i}$ be a sample $i$ of the travel time of link $a, \forall a \in \Gamma_{a}$. We assume that the link utilities are additive, to calculate the sample $i$ of the travel time of route $k, t_{k}^{i}$, as:

$$
t_{k}^{i}=\sum_{a \in \Gamma_{a}} t_{a}^{i} \delta_{a k}, \forall k \in \Omega^{o d} \wedge \forall(o, d) \in \Xi \wedge \forall i=1, \ldots, M
$$

where $\delta_{a k}$ is a binary variable that equals 1 if route $k$ travels on link $a$, or 0 otherwise.

For each sample $i=1, \ldots, M$, we locally solve the corresponding Prospect-based User Equilibrium problem. In more detail, each sample $t_{k}^{i}$ is evaluated in terms of travel time prospects $X_{k}\left(t_{k}^{i}\right)$ (Eq. 1) and framed as a gain or a loss depending on the reference point $T_{0}^{o d}$. We also have to calculate the probability $p_{k}$. For this, we discretize the travel time distributions into small bins and we calculate the surface area of each bin. This defines a set of probabilities for each route $k$ that connects the od pair. Based on the sample $t_{k}^{i}$, we identify the respective bin and the probability value. Once the time prospects are calculated, users choose the routes with the largest time prospects for each od pair, based on an all-or-nothing principle. The new temporary route flows, $Q_{k}^{\text {od,* }}$, are calculated by averaging all local choices made for each sample set. $Q_{k}^{o d, *}$ is used to update the new route flows $Q_{k}^{o d, j+1}$ at iteration $j+1$, as:

$$
Q_{k}^{o d, j+1}=Q_{k}^{o d, j}+\tau_{j}\left\{Q_{k}^{o d, *}-Q_{k}^{o d, j}\right\}, \forall k \in \Omega^{o d} \wedge \forall(o, d) \in \Xi
$$




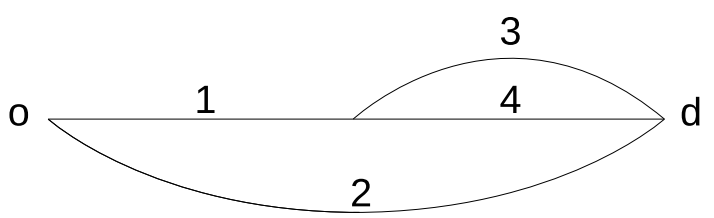

Figure 2: Traffic network composed by one od pair and three routes.

where $Q_{k}^{o d, j}$ represents the route flows at iteration $j$ of the MSA; and $\tau_{j}$ is the descent step of the MSA.

This process is repeated at each iteration $j$ of the MSA. To ensure the good convergence properties of the MSA, one should properly choose the descent step $\tau_{j}$. For the theoretical convergence of the algorithm, the following two conditions should be satisfied (Sheffi, 1985):

$$
\begin{aligned}
& \sum_{j=1}^{\infty} \tau_{j}=\infty \\
& \lim _{j \rightarrow \infty} \tau_{j} \rightarrow 0
\end{aligned}
$$

In this paper, we set $\tau_{j}=\frac{1}{j}$.

For the MSA convergence, we consider two stopping criteria:

- the number of violations $N(\lambda)$ (Sbayti et al., 2007), that represent the number of cases where $\left|Q_{k}^{o d, j+1}-Q_{k}^{o d, j}\right|$ is superior to a pre-defined path convergence threshold $\Phi$, for each od pair. The convergence is achieved when $N(\lambda) \leq \Phi$, for each od pair.

- a maximum number of $j$ iterations $N_{\max }$. That is $j \leq N_{\max }$.

We present a solution algorithm to calculate the Prospect-based User Equilibrium in Algorithm 1. A mesoscopic LWR traffic simulator (Leclercq and Becarie, 2012) is used to calculate time-dependent route costs, that account for dynamic effects such as congestion and spillback effects. In this paper, we split the total simulation period $T$ into smaller periods with duration $d t$. The dynamic traffic assignment framework is based on a quasi-static approximation for each period. For the first period $d t$, we calculate the Prospect-based User Equilibrium through the framework previously described. For the second period between $d t$ and $2 \times d t$, users make their choices based on the travel times at equilibrium from the previous period. This process is repeated for all small periods $d t$ until $T$. This re-assignment process allows the users' decisions to be time-dependent.

\subsection{Example of application: static traffic assignment on a 3 road network}

In this paper, the dynamic traffic assignment framework is based on a quasi-static approximation for each assignment period. Therefore, we investigate how the algorithm that is proposed to calculate the Prospect-based User Equilibrium (i.e. Algorithm 1) converges. We consider a simple static assignment problem. The test network is depicted in Fig. 2. It is composed by one od pair and four links. The route choice set is $\Omega^{o d}=\{(1,2) ;(1,3) ;(4)\}$. The total demand is $Q^{\text {od }}=100$.

The travel time $t_{k}$ of route $k$ depends on its circulating flow and is calculated as:

$$
t_{k}(\vec{Q})=\sum_{a \in \Gamma_{a}}\left(t_{a}+q_{a}(\vec{Q})+\epsilon_{a}\right) \delta_{a k}, \forall k \in \Omega^{o d} \wedge \forall(o, d) \in \Xi
$$

where $\vec{Q}$ is a vector that contains the three route flows, i.e. $\vec{Q}=\left(Q_{1}, Q_{2}, Q_{3}\right) ; t_{a}$ is the free-flow travel time of link $a$; $\Gamma_{a}$ is the set of links that define the traffic network; $\delta_{a k}$ is a binary variable that equals 1 if route $k$ travels on link $a$, or 
Input the traffic network, demand scenario, re-assignment period dt and simulation duration $T$.

Calculate the route choice set $\Omega^{o d}, \forall(o, d) \in \Xi$.

Initialize $j=1, \eta_{a}, \zeta_{a}, \alpha_{j=1}=1$.

Initialize the route flows $Q_{k}^{o d, j=1}=0, \forall k \in \Omega^{o d} \wedge \forall(o, d) \in \Xi$.

Perform an initial network loading.

for $m=1: T / d t$ do

while $N(\lambda) \geq \Phi$ or $j \leq N_{\max }$ do

Set $Q_{k}^{o d, j}=Q_{k}^{o d, j+1}, \forall k \in \Omega^{o d} \wedge \forall(o, d) \in \Xi$.

Discretize the link travel time distributions into $M$ samples.

Update the endogenous reference point $T_{0}^{o d}$.

Calculate the set of probabilities $p_{k}$ for each route $k$ of each od pair.

for $i=1$ to $M$ do

Update the set of samples $t_{k}^{i}, \forall k \in \Omega^{\text {od }} \wedge \forall(o, d) \in \Xi$.

Calculate the value function $v_{k}\left(t_{k}\right)$ (Eq. 2) and the weighting function $\omega(p)$ (Eq. 3),

$\forall k \in \Omega^{o d} \wedge \forall(o, d) \in \Xi$.

Determine the time prospect $X_{k}\left(t_{k}\right), \forall k \in \Omega^{o d} \wedge \forall(o, d) \in \Xi$ (Eq. 1).

For each od pair, users are assigned to the route with the maximum travel prospect based on an all-or-nothing assignment.

end

Update the new route flows $Q_{k}^{o d, *}, \forall k \in \Omega^{o d} \wedge \forall(o, d) \in \Xi$, based on an averaging of the users choices over all $M$ samples.

Update the route flows based on Eq. 14.

if Time-independent costs then

Perform a static loading of the network based on the new route flows and update the route travel

end times.

if Time-dependent costs then

Run the LWR mesoscopic simulator (Leclercq and Becarie, 2012) and update the route travel times. end

Based on the link travel times, fit a gamma distribution to update the set of $\eta_{a}$ and $\zeta_{a}$.

Calculate $N(\lambda)$

Update $\tau_{j}=\frac{1}{j}$.

Set $j=j+1$.

end

Save the route flows: $Q_{k}^{o d, j+1}, \forall k \in \Omega^{o d} \wedge \forall(o, d) \in \Xi$.

end

Algorithm 1: Dynamic implementation algorithm of the PT model previously described.

0 otherwise; $\epsilon_{a}$ is the error or uncertainty term associated to the travel time of link $a$; and $q_{a}$ is the flow of link $a$ that is calculated as:

$$
q_{a}=\sum_{a \in \Gamma_{a}} Q_{k} \delta_{a k}
$$

The free-flow link travel times are set to: $t_{1}=t_{2}=10 ; t_{3}=20$; and $t_{4}=50$. The error terms $\epsilon_{a}$ are gamma distributed with a mean equal to $t_{a}, \forall a \in \Gamma_{a}$ and a similar variance for $\sigma_{a}=2, \forall a \in \Gamma_{a}$. The parameters of the gamma distribution are updated as $\eta_{a}=\sigma_{a}, \forall a \in \Gamma_{a}$ for the scale parameter and $\zeta_{a}=\frac{t_{a}}{\sigma_{a}}, \forall a \in \Gamma_{a}$ for the shape parameter. For the Monte Carlo simulations, we set $M=5000$ samples.

The Prospect-based User Equilibrium is calculated for each reference point defined in Eq. 4 to Eq. 7 and the set of parameters $(\alpha, \beta, \lambda, \gamma, \phi)=(0.37,0.57,1.51,0.74,0.74)$ (Xu et al., 2011). We set three values of the acceptability 


\begin{tabular}{|c|c|c|c|c|c|c|}
\hline Equilibrium & $T_{0}^{\text {od }}$ & $Q_{1} / Q^{\text {od }}$ & $Q_{2} / Q^{\text {od }}$ & $Q_{3} / Q^{\text {od }}$ & $\mathrm{RMSE}$ & Gap \\
\hline DUE & $\sim$ & 0.30 & 0.20 & 0.50 & 0.3595 & 0.0000 \\
SUE & $\sim$ & 0.36 & 0.22 & 0.42 & 0.0005 & 0.1142 \\
Prospect Theory & Mean & 0.42 & 0.21 & 0.35 & 0.0012 & 0.3063 \\
Prospect Theory & Median & 0.47 & 0.26 & 0.27 & 0.0182 & 0.5741 \\
Prospect Theory & Mode & 0.40 & 0.23 & 0.37 & 0.0008 & 0.2293 \\
Prospect Theory & $\delta^{\text {od }}=0$ & 0.39 & 0.23 & 0.38 & 0.0008 & 0.3010 \\
Prospect Theory & $\delta^{\text {od }}=0.5$ & 0.53 & 0.29 & 0.18 & 0.0023 & 1.0113 \\
Prospect Theory & $\delta^{\text {od }}=1$ & 0.69 & 0.25 & 0.06 & 0.0547 & 2.0326 \\
\hline
\end{tabular}

Table 2: Route flows, RMSE and Gap values under Prospect-based User Equilibrium conditions for six settings of the reference point $T_{0}^{o d}$. The results for the DUE and SUE are also listed. These results correspond to the descent step iteration $j=30$.

tolerance band $\delta^{o d}=0,0.5,1$. As a reference, we also calculate the DUE and SUE. Note that, in this static implementation a simulation period $T$ is not considered and therefore only one iteration of the for loop (see Algorithm 1 ) is done.

We start by analyzing the convergence of Algorithm 1. We focus on the root-mean-square error (RMSE) and the relative Gap (Sbayti et al., 2007) criterion as convergence indicators for the traffic network depicted in Fig. 2. The RMSE at the $j$-th iteration of the MSA is calculated as:

$$
R M S E^{j}=\sqrt{\frac{1}{\left|\Omega^{o d}\right|} \sum_{k}\left|Q_{k}^{o d, *}-Q_{k}^{o d, j}\right|}
$$

where |.| is the number of routes listed in $\Omega^{\text {od }}$.

The relative Gap (Sbayti et al., 2007) at the $j$-th iteration of the MSA is calculated as:

$$
G a p^{j}=\frac{\sum_{k} Q_{k}^{o d}\left(\bar{t}_{k}^{o d}-\min \left(\bar{t}_{k}^{o d}\right)\right)}{Q^{o d} \min \left(\bar{t}_{k}^{o d}\right)}
$$

The relative $G_{a p}{ }^{j}$ is an equilibrium indicator that is 0 under DUE conditions. This means that all users have chosen the routes with the minimal travel times. The $G a p^{j}$ is larger than 0 for the SUE, however small, due to the uncertainty of the travel times.

To analyze the convergence of Algorithm 1, we run 30 iterations of the MSA procedure for the DUE, SUE and the different settings of the Prospect Theory as previously described. Fig. 3 depicts the evolution of the RMSE, relative GAP and the different reference points $T_{0}^{o d}$ as function of the $j$-th MSA iteration. The route flows as well as the RMSE and relative GAP values for the 30-th iteration are listed in Table 2.

The evolution of the RMSE as function of the $j$-th MSA iteration shows the good convergence of Algorithm 1. As $j$ increases, the RMSE value decreases towards 0 , for all model settings considered for the Prospect Theory. The reference point $T_{0}^{o d}$ also converges to a constant value as we achieve the equilibrium conditions of the traffic network. The relative Gap acts as an indicator that tells us how far we are from the DUE. The results depicted in Fig. 3 show that the implementation of Prospect Theory considering the reference points $T_{0}^{o d}$ defined by Eq. 4 to Eq. 6 leads to network equilibrium conditions that are very close to the DUE and SUE. Nevertheless, this is not similar for the reference point $T_{0}^{o d}$ defined by Eq. 7. For $\delta^{o d}=0$, the evolution of the relative Gap converges to similar values as the DUE and SUE. For larger $\delta^{o d}$ values, the relative Gap converges to larger values. The latter evidences that the network equilibrium is different than the DUE and SUE. To better dissect these results evidenced by the relative Gap, we analyze the route flows at equilibrium listed in Table 2, for the descent step iteration $j=30$. Fig. 4 depicts the distribution of travel times, value of function $v\left(t_{k}\right)$, probability distributions and time prospect distributions for the reference point calibration defined in Eq. 7, considering three $\delta^{o d}$ values. These results correspond to the route flows at equilibrium listed in Table 2. For $\delta^{o d}=0$, we are close to the DUE and SUE as previously evidenced by the Gap values and the 

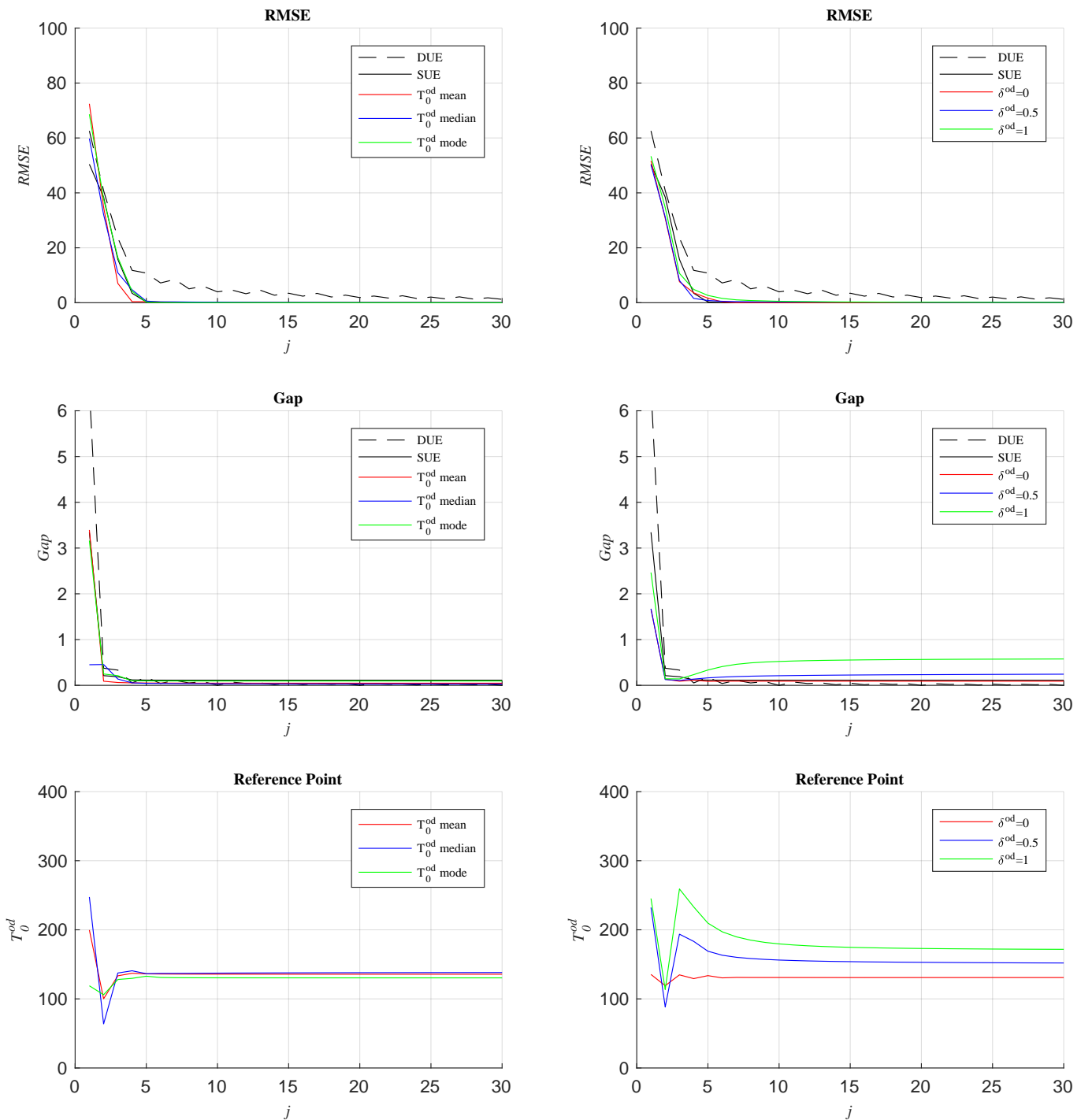

Figure 3: RMSE and Gap values as function of the MSA descent iteration $j$. The results are shown for the DUE, SUE and the Prospect-based User Equilibrium considering different settings of the reference point. The evolution of the six endogenous reference points $T^{\text {od }}$ as function of the MSA descent iteration $j$ are also represented. The left plots represent the results for the mean, median and mode setting of $T^{\text {od }}$. The right plots represent the three settings of $\delta^{\text {od }}$ for $T^{\text {od }}$ 

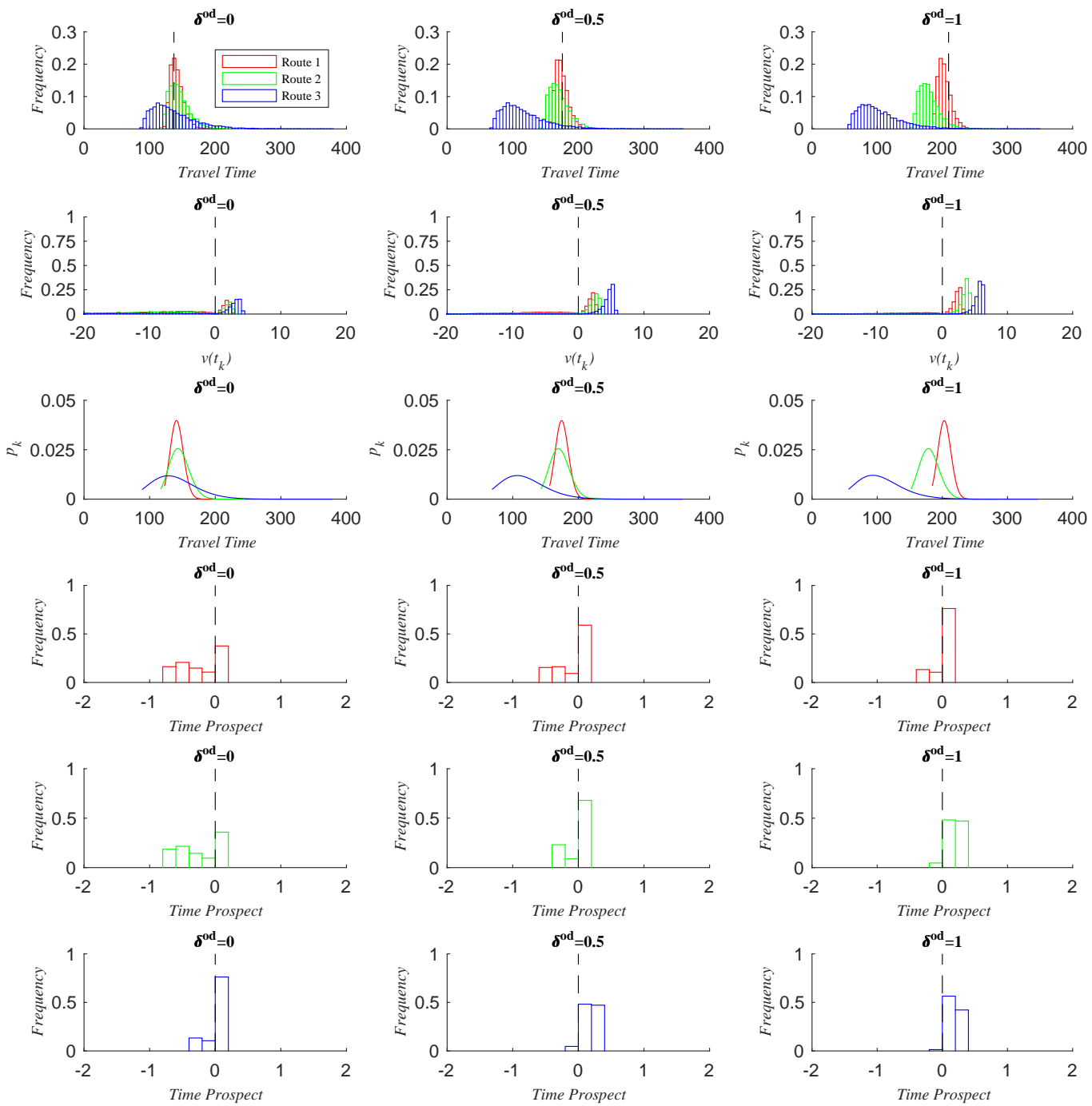

Figure 4: Distributions of travel times, value function $v\left(t_{k}\right)$, probability distributions $p_{k}$ and time prospects $X_{k}\left(t_{k}\right)$ for three settings of the reference point defined in Eq. 7. The results in red refer to route 1, in green to route 2 and in blue to route 3 . Three values of $\delta^{o d}$ are considered: $0,0.5$ and 1 . 
route flows at equilibrium. An increase of $\delta^{\text {od }}$ leads to an increase of the reference point value and the range of the travel times distributions that are framed as gains also increases (see the $v\left(t_{k}\right)$ distributions in Fig. 4). But, increasing the reference point value does not necessarily mean that users will choose the route(s) with the minimum(minimal) travel time(s). For $\delta^{o d}=1$, the distribution of travel times is lower for route 3 than the other two routes. The value function indicates that one might potentially have larger gains in choosing route 1. Nevertheless, the probability of facing these gains for route 1 is much lower than for the other two routes (see the probability distribution in Fig. 4). The time prospect (Eq. 1) depends on the balance between the value of the possible gains with the weighting of the outcome probabilities of facing these gains. Therefore, routes 1 and 2 happen to have a larger number of prospects framed as the maximum ones for a larger number of Monte Carlo samples. These two routes are then chosen more often than route 1 .

In summary, we show that the tenets of disutility minimization (i.e. users that chose to minimize their own travel times) and prospect maximization are different. These differences strongly depend on the setting of the reference point.

\section{Dynamic Prospect-based User Equilibrium}

\subsection{Synthetic Manhattan traffic network settings}

In this section, the dynamic implementation of Prospect Theory is done on a synthetic Manhattan network, depicted in Fig. 5. It is composed by 134 links with a similar length of 100 meters. There are traffic lights located in all intersections, with a cycle of 45 seconds. The traffic lights located in the horizontal links have a green light duration of 30 seconds.

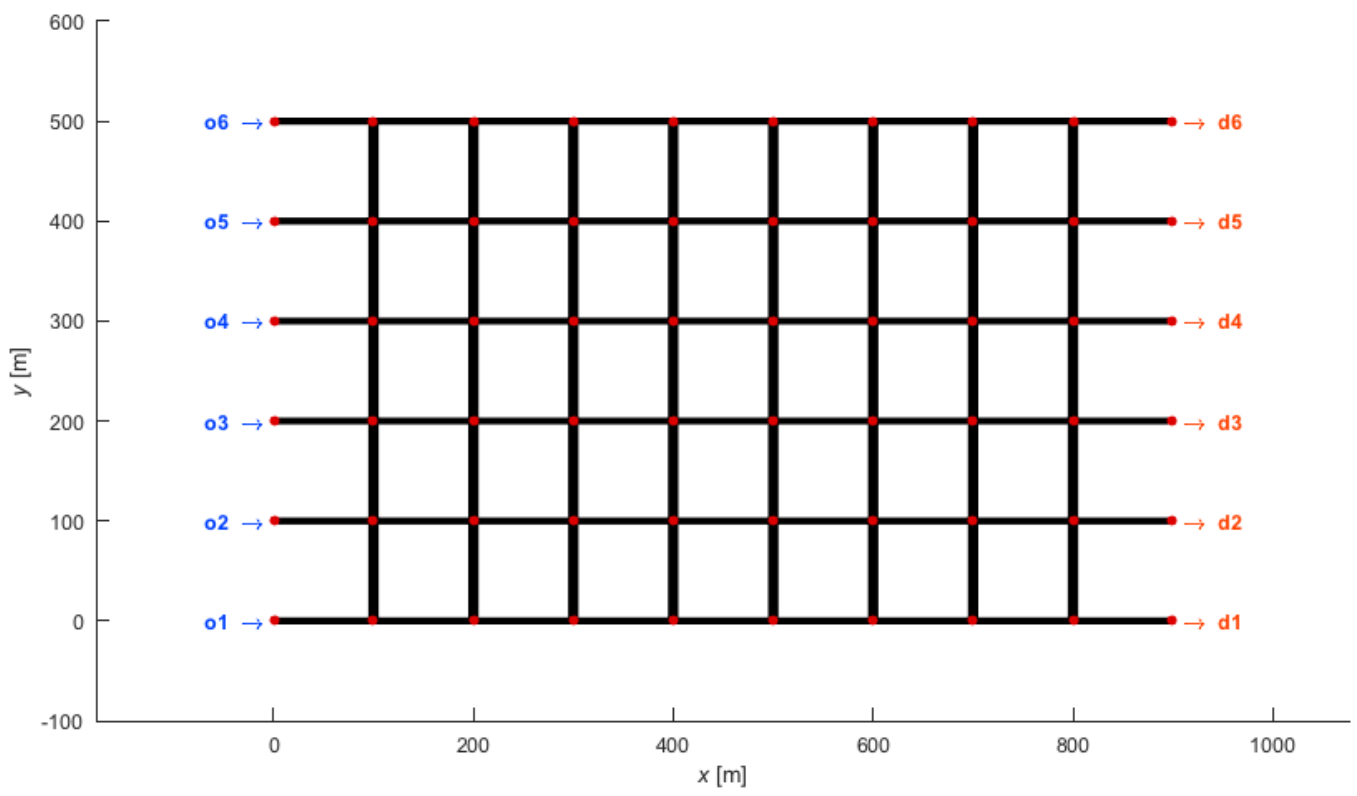

Figure 5: Manhattan network. The origins are shown by the indicators from o1 to o6 and the destinations from d1 to d6

The fundamental diagram, that regulates the traffic states in each lane, is triangular and characterized by the following parameters: free-flow speed $u=15(\mathrm{~m} / \mathrm{s})$; wave speed $w=5(\mathrm{~m} / \mathrm{s})$; and a jam density $k_{\text {jam }}=0.2(\mathrm{veh} / \mathrm{m} / \mathrm{lane})$. The traffic network has six entries and exits. They are identified in Fig. 5, by o1 to o6 for the entries and by d1 to d6 
for the exits. There is a constant inflow (i.e. demand) of 0.5 (veh/s) at each entry, that is equally assigned to the six exits during the assignment period. The entry network links have two lanes. Vehicles are equally assigned on each lane. There are no capacity restrictions at the exits. In total, there are 36 od pairs. For each od pair, the choice set $\Omega^{o d}$ is calculated based on $3 \mathrm{~K}$-shortest paths per od pair. This yields a total of 108 routes.

The total simulation period is $T=3000$ seconds and the network equilibrium is calculated each 250 seconds. This means that vehicles are re-assigned at each period of 250 seconds based on the traffic conditions of the previous assignment period. We set $\Phi=0$ and $N_{\max }=250$ for the MSA convergence and $M=5000$ samples for the Monte Carlo simulations. The dynamic Prospect-based User Equilibrium is calculated based on the reference points defined in Eq. 4 to Eq. 7. For the acceptability risk tolerance band, we set $\delta^{o d}=0,1, \infty$. Unless clearly stated otherwise (in Sect. 4.3), we consider the users' risk-aversion and risk-seeking parameters stated in Xu et al. (2011) for all simulation scenarios. In Table 3, we label each simulation scenario considered in this section.

\begin{tabular}{|ccc|}
\hline Model & $T_{0}^{\text {od }}$ & ID Model \\
\hline DUE & $\sim$ & 1 \\
SUE & $\sim$ & 2 \\
PT & Mean & 3 \\
PT & Median & 4 \\
PT & Mode & 5 \\
PT & $\delta^{o d}=0$ & 6 \\
PT & $\delta^{o d}=1$ & 7 \\
PT & $\delta^{o d}=\infty$ & 8 \\
\hline
\end{tabular}

Table 3: Models IDs for the DUE, SUE and the implementation of Prospect Theory considering the reference points defined in Eq. 4 to Eq. 7. Three $\delta^{\text {od }}$ values are considered.

\subsection{Analysis of the network performance at an individual level}

In this section, we analyze the traffic network performance at an individual level. For this, we investigate the differences between the route flow patterns under the dynamic Prospect-based User Equilibrium and the benchmarks DUE and SUE. Fig. 6 and Fig. 7 depict the route flows for all 36 od pairs and all eight simulation scenarios. We refer to these scenarios following the labels listed in Table 3. Fig. 8 depicts the distributions of the average travel times per route for each of the eight scenarios. As one can observe, the route flows are very similar between the dynamic Prospect-based User Equilibrium, calculated for the settings of the reference point such as the mean, median and mode (i.e. models 3 to 5) and the benchmarks DUE and SUE (i.e. models 1 and 2). This is due to the low number of routes that are evaluated in terms of time prospects. When the reference point $T_{0}^{o d}$ is set as the mean, median or mode of the travel times, only one or two out of three routes are mainly framed as prospects of gains. The routes with the minimal travel times tend to be the ones with the largest time prospects and are the chosen ones. These results also confirm the ones discussed in Sect. 3.2. The distributions of the average travel times per route (Fig. 8) also show the similarities between the dynamic Prospect-based User Equilibrium, for the reference points defined as the mean, median and mode, and the benchmarks DUE and SUE. Nevertheless, when the reference point $T_{0}^{o d}$ is defined as in Eq. 7 (i.e. models 6 to 8), the route flows under the dynamic Prospect-based User Equilibrium are different than the benchmarks DUE and SUE. When $\delta^{o d}=0$, the route flows are very close to the ones of the benchmarks DUE and SUE, for the reasons we have just mentioned before. As $\delta^{o d}$ increases, the value of the reference point $T_{0}^{o d}$ also increases. Routes with larger travel times will also be valued as possible gains. Depending on the weighting of the outcome probabilities, the time prospects of these routes with larger travel times might be framed as prospects of gains and then chosen by the drivers. With the increase of $\delta^{\text {od }}$ drivers start to switch to different routes and in some cases to routes with larger travel times than the minimal one for their od pair. In fact, this result is also evidenced by the distributions of average travel times per routes depicted in Fig. 8. One can observe that as $\delta^{\text {od }}$, the number of routes with larger travel times also increases.

In summary, we show that the calculation of the dynamic Prospect-based User Equilibrium, considering the setting of the reference point $T_{0}^{o d}$ defined in Eq. 4 to Eq. 6, provides similar results as the benchmarks DUE and SUE. 

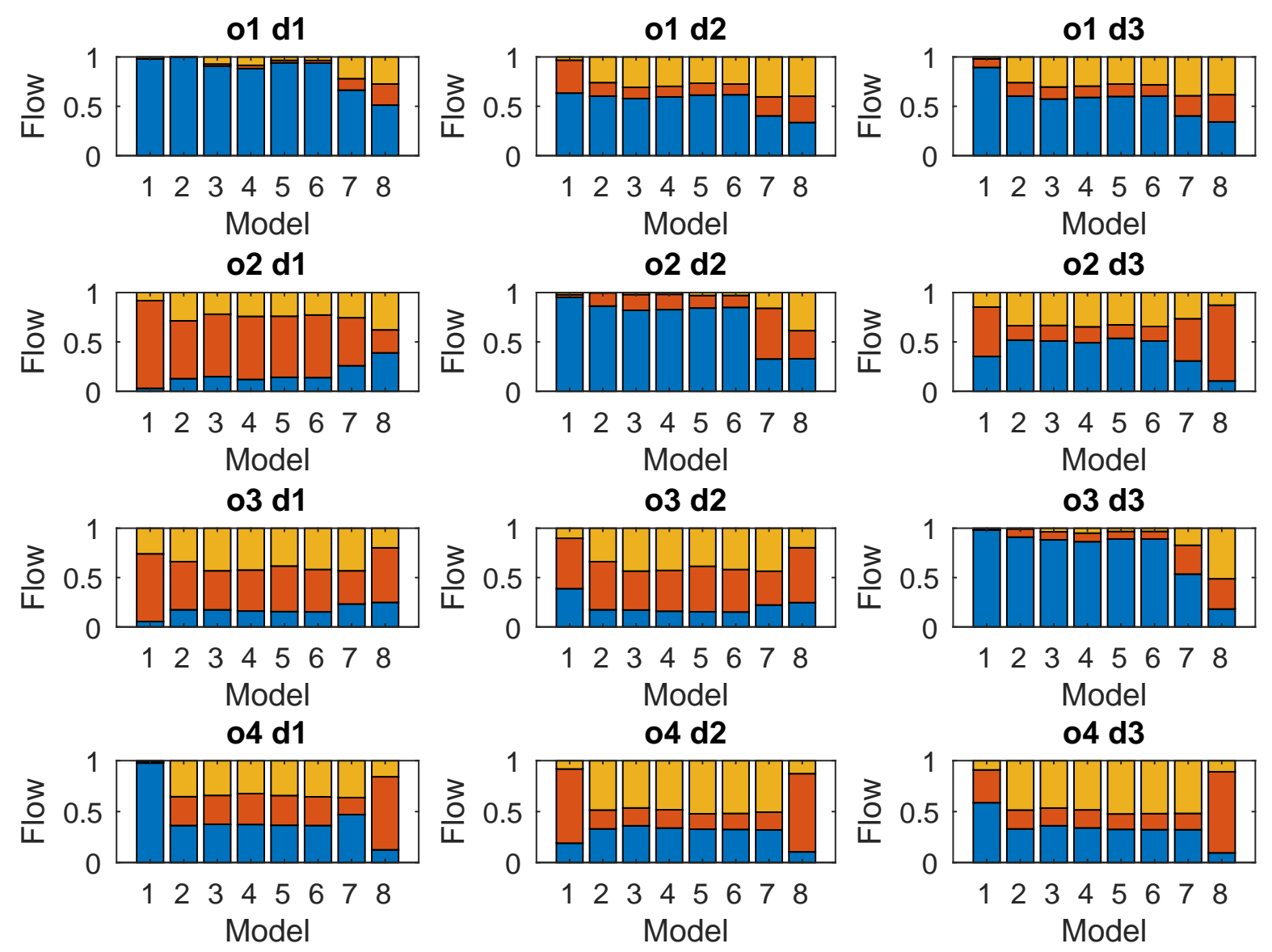

$05 \mathrm{~d} 1$

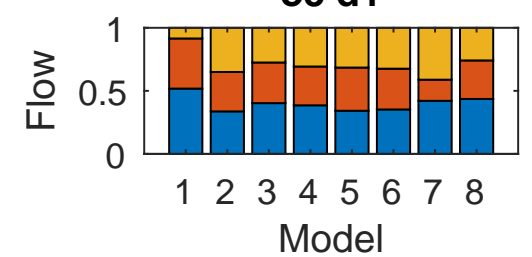

$05 \mathrm{~d} 2$

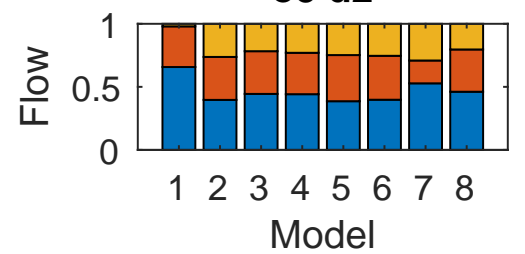

Model

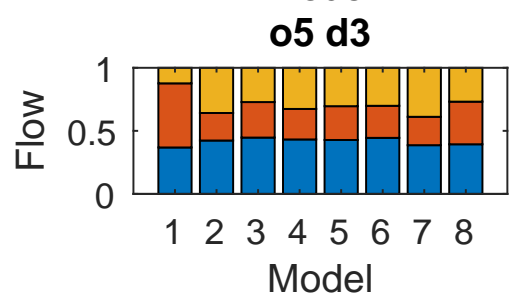

$06 \mathrm{~d} 1$

$06 \mathrm{~d} 2$
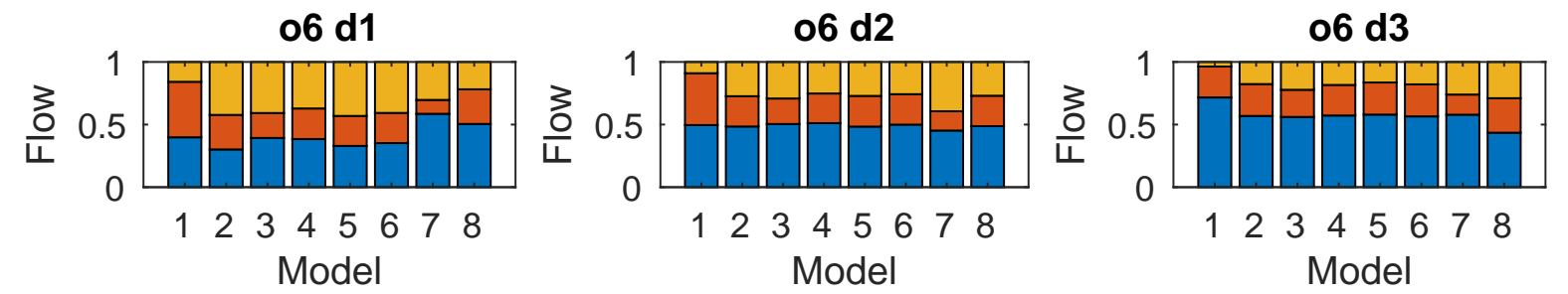

Figure 6: Route flow distributions for the 8 simulation scenarios and for the od pairs: $o=1, \ldots, 6$; and $d=1,2,3$. Each simulation scenario is identified by the Model ID as listed in Table 3. 

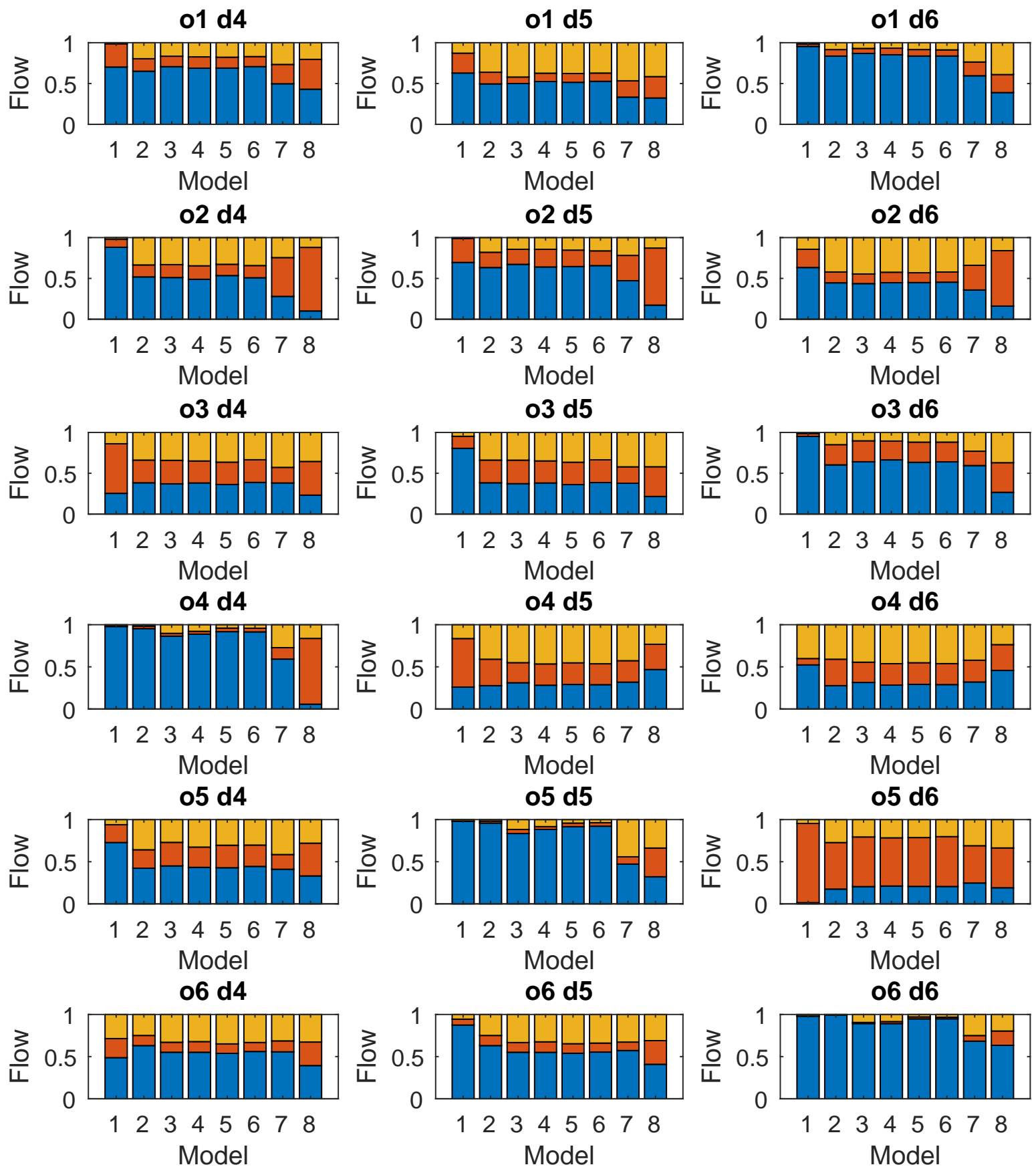

Figure 7: Same as in Fig. 7, but for the od pairs: $o=1, \ldots, 6$; and $d=4,5,6$. 

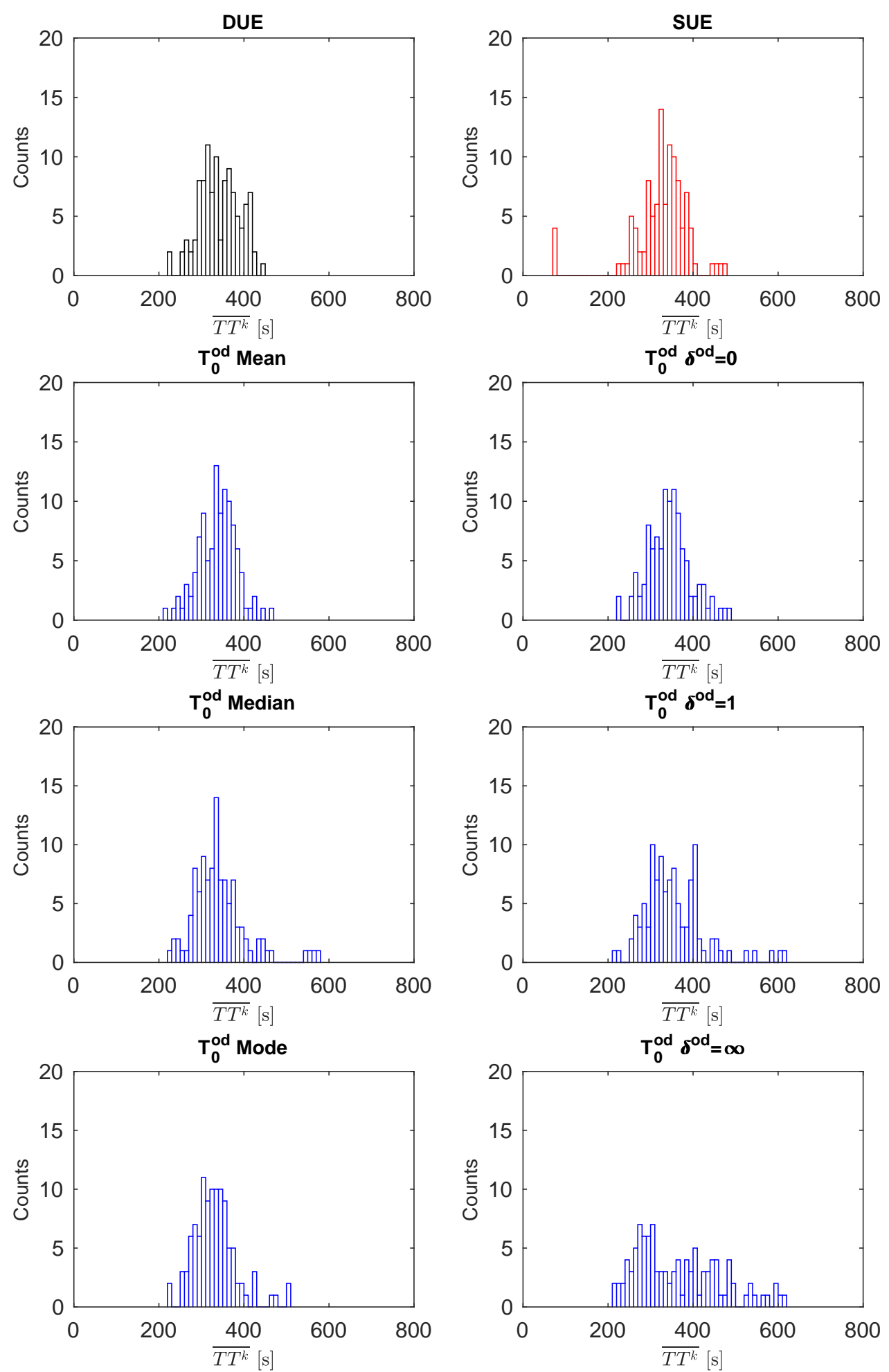

Figure 8: Average route travel time distributions for the DUE, SUE and different settings of Prospect Theory (see Table 3 for more details). 
However, this is not the case for the reference point defined in Eq. 7. This strengths the importance of the reference point calibration to calculate the Prospect-based User Equilibrium, also in the dynamic context.

\subsection{Sensitivity of the dynamic Prospect-based User Equilibrium to $T_{0}^{o d}$ and the sets of the risk-aversion and risk- seeking parameters}

In this section, we analyze the sensitivity of the dynamic Prospect-based User Equilibrium to changes in the setting of the reference point $T_{0}^{o d}$ and in the set of the users' risk-aversion and risk-seeking parameters. For this purpose, we:

i. fix the set of users' risk aversion parameters $(\alpha, \beta, \lambda, \gamma, \phi)$ and change $T_{0}^{o d}$ as defined by Eq. 4 to Eq. 7.

ii. fix $T_{0}^{o d}$ and change the set of users' risk aversion parameters $(\alpha, \beta, \lambda, \gamma, \phi)$. We consider the set of parameters defined by Tversky and Kahneman (1992) and the one by Xu et al. (2011).

\begin{tabular}{|c|ccccc|}
\hline \multicolumn{7}{|c|}{ Tversky and Kahneman (1992) parameters } \\
\hline & Median & Mode & $\delta^{\text {od }}=0$ & $\delta^{\text {od }}=1$ & $\delta^{\text {od }}=\infty$ \\
\hline Mean & 0.027 & 0.017 & 0.023 & 0.102 & 0.265 \\
Median & $\sim$ & 0.015 & 0.018 & 0.101 & 0.262 \\
Mode & $\sim$ & $\sim$ & 0.018 & 0.101 & 0.265 \\
$\delta^{\text {od }}=0$ & $\sim$ & $\sim$ & $\sim$ & 0.100 & 0.261 \\
$\delta^{\text {od }}=1$ & $\sim$ & $\sim$ & $\sim$ & $\sim$ & 0.211 \\
\hline
\end{tabular}

\begin{tabular}{|c|ccccc|}
\hline \multicolumn{7}{|c|}{ Xu et al. (2011) parameters } \\
\hline & Median & Mode & $\delta^{\text {od }}=0$ & $\delta^{\text {od }}=1$ & $\delta^{\text {od }}=\infty$ \\
\hline Mean & 0.016 & 0.031 & 0.028 & 0.142 & 0.281 \\
Median & $\sim$ & 0.025 & 0.020 & 0.142 & 0.280 \\
Mode & $\sim$ & $\sim$ & 0.013 & 0.155 & 0.288 \\
$\delta^{\text {od }}=0$ & $\sim$ & $\sim$ & $\sim$ & 0.154 & 0.289 \\
$\delta^{\text {od }}=1$ & $\sim$ & $\sim$ & $\sim$ & $\sim$ & 0.212 \\
\hline
\end{tabular}

Table 4: Sensitivity of the Prospect Theory to the reference point $T_{0}^{o d}$. Top: Results for the Tversky and Kahneman (1992) parameters. Bottom: Results for the Xu et al. (2011) parameters.

\begin{tabular}{|c|c|c|c|c|c|}
\hline Mean & Median & Mode & $\delta^{\text {od }}=0$ & $\delta^{\text {od }}=1$ & $\delta^{\text {od }}=\infty$ \\
\hline 0.040 & 0.033 & 0.021 & 0.025 & 0.087 & 0.180 \\
\hline
\end{tabular}

Table 5: Sensitivity of the Prospect Theory to the user's risk-aversion parameters $(\alpha, \beta, \lambda, \gamma, \phi)$.

For this sensitivity analysis, we calculate the sum square of the residuals between the route flows at equilibrium for all possible combinations of the Prospect Theory implementation. The results for case $i$ and $i i$ are listed in Table 4 and Table 5, respectively. We first focus on the sum square of the residuals for a change in the reference point as defined in Eq. 4 to Eq. 6. The sum square of the residuals are of the order of $\sim 0.01-0.03$, for both sets of the users' risk-aversion and risk-seeking parameters. These are of the same magnitude order as for the case of a change in the set of the users' risk-aversion and risk-seeking parameters and fixing reference point $T_{0}^{o d}$. When the reference point is based on the acceptability risk-tolerance band (i.e. Eq. 7), the differences become much more significant. In this case, the Prospect-based User Equilibrium is more sensitive to a change in the reference point than in the set of users' risk-aversion and risk-seeking parameters.

\subsection{Analysis of the traffic network performance at an aggregated level}

In this section, we analyze the traffic network performance under the dynamic Prospect-based User Equilibrium conditions compared to the benchmarks DUE and SUE. The network performance is evaluated through the Macroscopic Fundamental Diagram (MFD), i.e. at an aggregated network level. We are interested in investigating the critical 

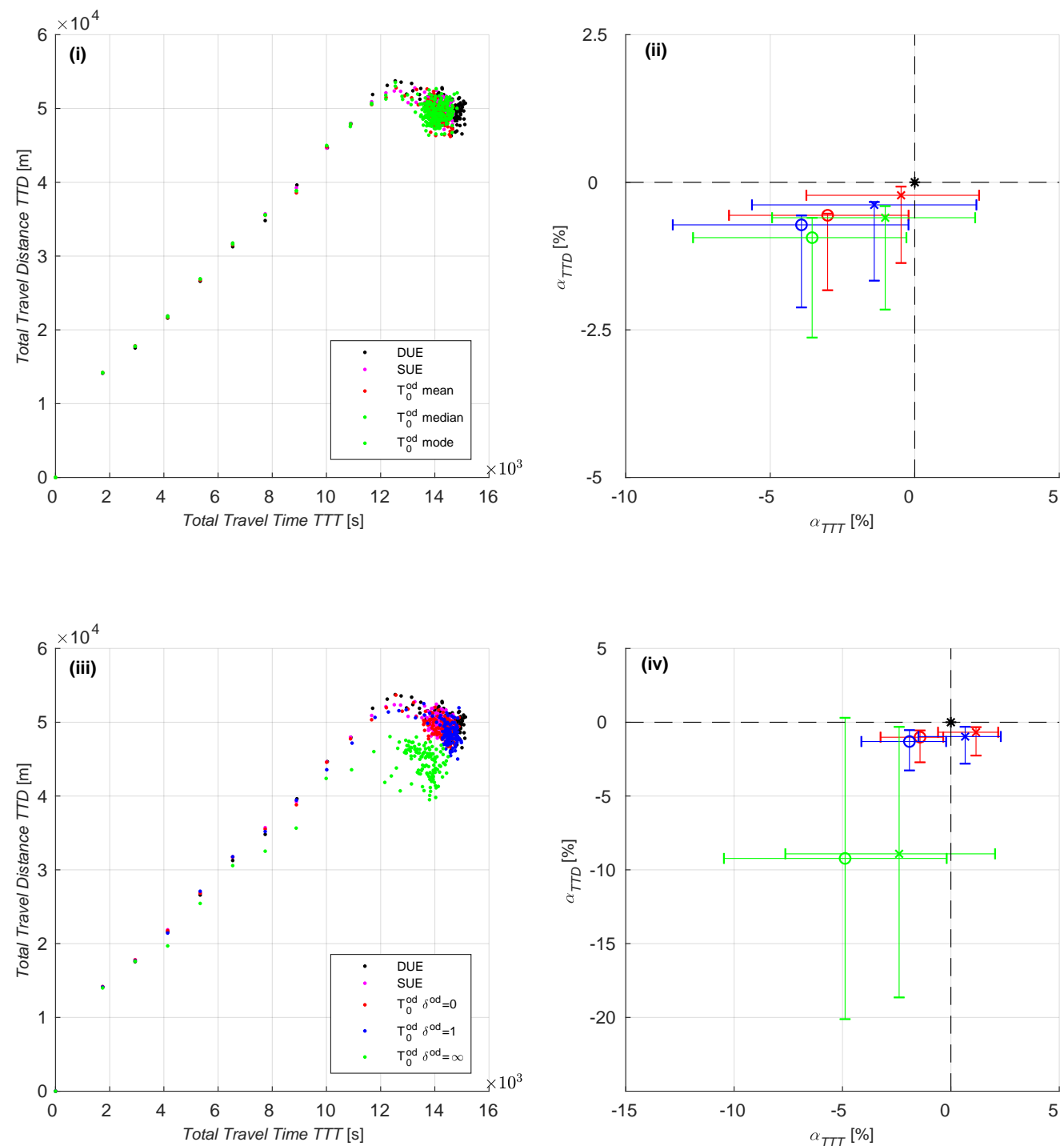

Figure 9: Total travel distance (TTD) [in m] as function of the total travel time (TTT) [in s] and $\alpha_{T T D}$ versus $\alpha_{T T T}$. (i) The results are depicted for the DUE, SUE and three settings of Prospect Theory considering the reference points defined in Eq. 4 to Eq. 6 . (ii) The results are depicted for the three settings of Prospect Theory as in (i) compared to the benchmarks DUE and SUE. (iii) The results are depicted for the DUE, SUE and three settings of Prospect Theory considering the reference point defined in Eq. 7 and three values of $\delta^{o d}=0,1, \infty$. (iv) The results are depicted for the three settings of $\delta^{\text {od }}$ compared to the benchmarks DUE and SUE.

accumulation of vehicles $n_{c}$ and the critical production $P_{c}$ of the MFD obtained for models 3 to 8 in comparison to the benchmarks DUE and SUE (i.e. models 1 and 2). This allows to analyze the differences in terms of the mean speed as well as the network internal and outflow capacities. Fig. 9 depicts the evolution of the total travel distance (TTD) as function of the total travel time (TTT). Fig. 10 depicts the evolution of the outflow $Q_{\text {out }}$ as function of the total travel time (TTT). As one can observe, there is a large points overlap of the MFD functions as well as of the outflow $Q_{\text {out }}$ versus TTT. To better highlight the differences between the models, we define three criteria that represent: 

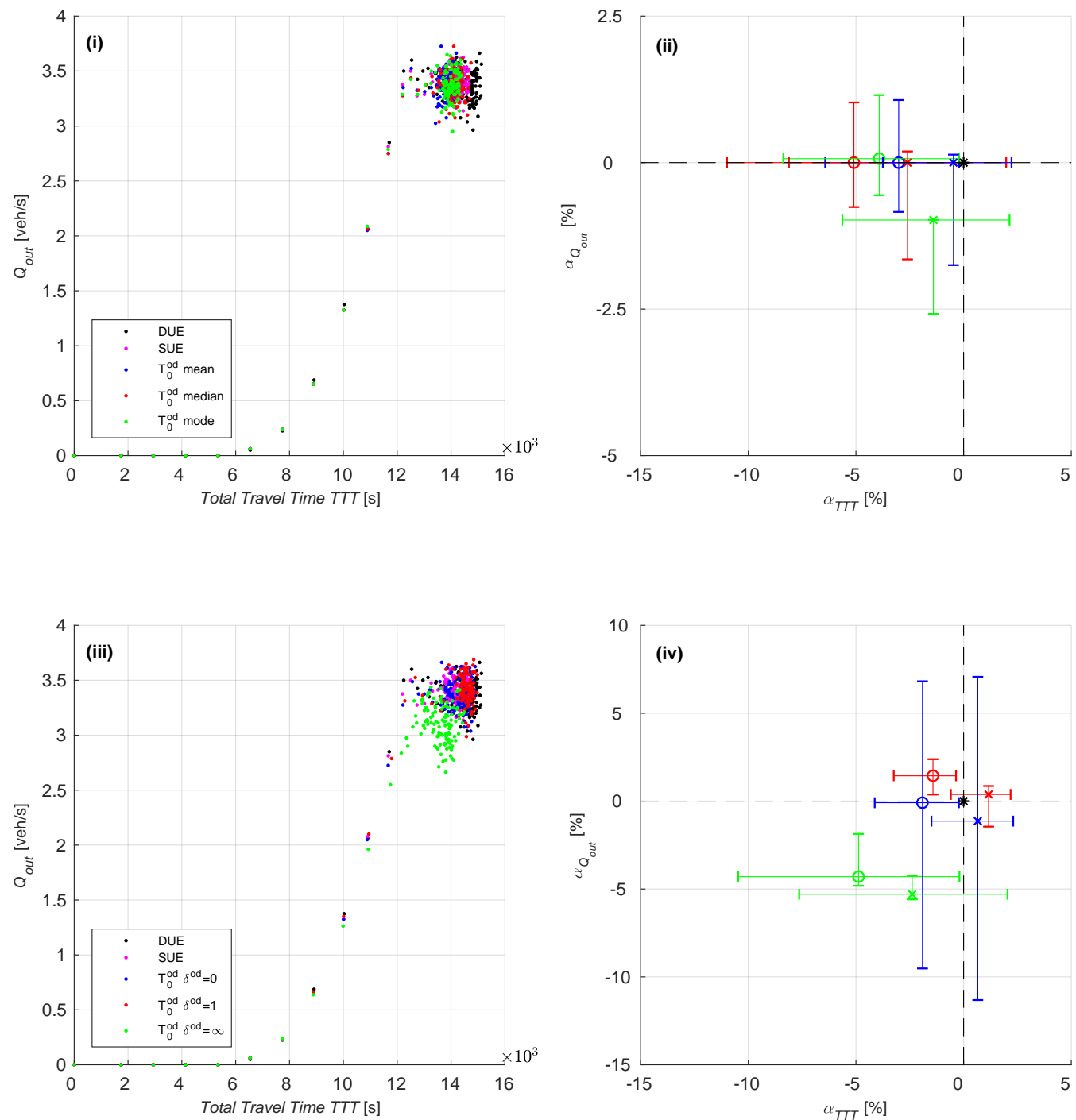

Figure 10: Vehicles outflow $\left(Q_{\text {out }}\right)$ as function of the Total Travel Time (TTT) and $\alpha_{Q_{\text {out }}}$ versus $\alpha_{T T T}$. (i) The results are depicted for the DUE, SUE and three settings of Prospect Theory considering the reference points defined in Eq. 4 to Eq. 6 . (ii) The results are depicted for the three settings of Prospect Theory as in (i) compared to the benchmarks DUE and SUE. (iii) The results are depicted for the DUE, SUE and three settings of Prospect Theory considering the reference point defined in Eq. 7 and three values of $\delta^{o d}=0,1, \infty$. (iv) The results are depicted for the three settings of $\delta^{o d}$ compared to the benchmarks DUE and SUE. 
- the relative difference between the average TTD of the different Prospect Theory settings $\left(\overline{T T D^{*}}\right)$ and of the benchmarks DUE and SUE $\left(\overline{T T D^{r e f}}\right)$ :

$$
\alpha_{T T D}=\frac{\overline{T T D^{*}}-\overline{T T D^{r e f}}}{\overline{T T D^{r e f}}} \times 100
$$

- the relative difference between the average TTT of the different Prospect Theory settings $\left(\overline{T T T^{*}}\right)$ and of the benchmarks DUE and SUE $\left(\overline{T T T^{r e f}}\right)$ :

$$
\alpha_{T T T}=\frac{\overline{T T T^{*}}-\overline{T T T^{r e f}}}{\overline{T T T^{r e f}}} \times 100
$$

- the relative difference between the average $Q_{\text {out }}$ of the different Prospect Theory settings $\left(\overline{Q_{o u t}^{*}}\right)$ and of the benchmarks DUE and SUE $\left(\overline{Q_{\text {out }}^{\text {ref }}}\right)$ :

$$
\alpha_{Q_{\text {out }}}=\frac{\overline{Q_{\text {out }}^{*}}-\overline{Q_{\text {out }}^{\text {ref }}}}{\overline{Q_{\text {out }}^{\text {ref }}}} \times 100
$$

The average values for TTD, TTT and $Q_{\text {out }}$ are calculated for the simulation interval between 500 and 2500 seconds, for all models. Based on this, we calculate $\alpha_{T T D}, \alpha_{T T T}$ and $\alpha_{Q_{\text {out }}}$ and we estimate confidence intervals for these three criteria. The results are shown in Fig. 9 for $\alpha_{T T D}$ as function of $\alpha_{T T T}$. Fig. 10 depicts the results for $\alpha_{Q_{\text {out }}}$ as function of $\alpha_{T T T}$. The differences between the dynamic Prospect-based User Equilibrium and the DUE are represented by the circle dots and for the SUE are represented by the cross dots. These three criteria allow us to analyze the changes in the network capacity and performance. If $\alpha_{T T D}<0$, the network internal capacity decreases compared with the benchmarks DUE and SUE. The accumulation of vehicles inside the network is higher and congestion might spread backwards, increasing the average waiting times for vehicles to enter the network. The network inflow capacity is reduced. If $\alpha_{T T T}<0$, the mean speed of vehicles inside the network is higher than the benchmarks DUE and SUE. If $\alpha_{Q_{\text {out }}}>0$, the outflow capacity of the network is higher compared against the benchmarks DUE and SUE.

We first focus on the analysis of the network performance, comparing the dynamic Prospect-based User Equilibrium, when the reference point are set as the mean, median and mode (i.e. models 3 to 5), and the benchmarks DUE and SUE. We do not observe any significant differences in terms of the network internal and outflow capacities. However, there is an increase of $\sim 4 \%$ of the vehicles' mean speed inside the network. Nevertheless, one can observe significant differences in terms of the network internal and outflow capacities, when the reference point is defined based on the acceptability risk tolerance band (see Eq. 7). As $\delta^{\text {od }}$ increases, the network internal capacity decreases because drivers choose routes with larger travel times as previously discussed in Sect. 4.2. They need more time to complete their trips and increase the level of congestion in the traffic network, reducing its internal capacity. This also implies a reduction in the outflow capacity of the network as depicted in Fig. 10.

\section{Conclusions}

In this paper, we revisit the concept of Prospect-based User Equilibrium (Connors and Sumalee, 2009; Sumalee et al., 2009; Xu et al., 2011) and extend it to the dynamic traffic assignment case. We discuss a solution framework that considers Monte Carlo simulations to account for the distributions of route travel times. We propose a solution algorithm that is based on the Method of Successive Averages. In this paper, the dynamic traffic assignment framework is based on a quasi-static approximation. We then analyze how the algorithm converges in a simple static test scenario, where we consider a network composed by one od pair and three routes. The algorithm shows good convergence properties by analyzing the evolution of the RMSE and Gap criterion as function of the MSA descent step. The values of the reference points also converge to a constant value as the MSA descent step increases. We also analyze the dynamic Prospect-based User Equilibrium compared to the references DUE and SUE. These tests are performed on a synthetic Manhattan network. A dynamic LWR mesoscopic dynamic simulator (Leclercq and Becarie, 2012) is used 
to calculate time-dependent route costs that account for congestion and spillback effects. Both results in the static and dynamic contexts enhance the important role of the reference point $T_{0}^{\text {od }}$ on the route flow patterns at equilibrium. We show that under the Prospect-based User Equilibrium, the setting of reference points defined as the mean (Eq. 4), median (Eq. 5) and mode (Eq. 6) lead to route flow patterns that are very similar to those of the DUE and SUE. On the other hand, this is not the same for the reference point defined in Eq. 7. Our results also enhance that a disutility minimizer (i.e. users that want to minimize their own travel times) and prospect maximizer behaviors are different. As $\delta^{o d}$ increases, routes with longer travel times than the minimal one might be framed more often as time prospects of gains and therefore more often chosen. This depends on the balance between the value of possible gains and the weighting of the probability of facing this outcome. In this paper, we also show that the Prospect-based User Equilibrium is more sensitive to a change in the reference point $T_{0}^{o d}$ than in the set of the users' risk-aversion and risk-seeking behavior. We also show that as $\delta^{\text {od }}$ increases, the network internal and outflow performances decreases compared to the DUE and SUE, because drivers chose routes with longer travel times. Nevertheless, no significant differences are observed in terms of the network performance when the reference point is defined as the mean, median and mode of the travel times.

As future research, we plan to do a calibration and validation of the Prospect-based User Equilibrium. This work can also be extended to account for heterogeneous population of users, for example, with preferences for their transportation mode. The idea is to split the heterogeneous population of users into homogeneous classes with similar preferences in terms of prospects. For each class, one defines a $T_{0}^{o d}$ and a set of the risk-aversion parameters.

\section{Data availability statement}

No data were used to support this study.

\section{References}

Avineri, E., 2004. A cumulative prospect theory approach to passengers behavior modeling: Waiting time paradox revisited. Journal of Intelligent Transportation Systems 8, 195-204.

URL https : //dx.doi.org/10.1080/15472450490523856

Avineri, E., 2006. The effect of reference point on stochastic network equilibrium. Transportation Science 4 (4), 409-420. URL https: //dx.doi.org/10.1287/trsc.1060.0158

Avineri, E., Bovy, P., 2008. Identification of parameters for a prospect theory model for travel choice analysis. Transportation Research Record 2082, 141-147. URL https : //dx.doi.org/10.3141/2082-17

Avineri, E., Prashker, J., 2004. Violations of expected utility theory in route-choice stated preferences: Certainty effect and inflation of small probabilities. Transportation Research Record: Journal of the Transportation Research Board 1894, $222-229$. URL https : //dx.doi.org/10.3141/1894-23

Bates, J., Polak, J., Jones, P., Cook, A., 2000. The valuation of reliability for personal travel. Transportation Research Part E: Logistics and Transportation Review 37 (2), 191-229. URL https : //dx.doi.org/10.1016/S1366-5545(00)00011-9

Batista, S. F. A., Zhao, C.-L., Leclercq, L., 2018. Effects of users bounded rationality on a traffic network performance: A simulation study. Journal of Advanced Transportation.

Bell, M. G. H., 2000. A game theory approach to measuring the performance reliability of transport networks. Transportation Research Part B: Methodological 34, 533546.

URL https : //dx.doi.org/10.1016/S0191-2615(99)00042-9

Bell, M. G. H., Cassir, C., 2002. Risk-averse user equilibrium traffic assignment: an application of game theory. Transportation Research Part B: Methodological $36(8), 671-681$.

URL https : //dx.doi .org/10.1016/S0191-2615(01)00022-4

Ben-Elia, E., Shiftan, Y., 2010. Which road do i take? a learning-based model of route-choice behavior with real-time information. Transportation Research Part A: Policy and Practice 44, 249-264.

URL https://dx.doi.org/10.1016/j.tra.2010.01.007

Ceder, A., Chowdhury, S., Taghipouran, N., Olsen, J., 2013. Modelling public-transport users behaviour at connection point. Transport Policy 27, $112-122$.

URL https://dx.doi.org/10.1016/j.tranpol.2013.01.002

Chen, A., Zhou, Z., 2010. The $\alpha$-reliable mean-excess traffic equilibrium model with stochastic travel times. Transportation Research Part B: Methodological 44 (4), $493-513$.

URL http://dx.doi.org/10.1016/j.trb.2009.11.003

Chen, A., Zhou, Z., Lam, W. H. K., 2011. Modeling stochastic perception error in the mean-excess traffic equilibrium model. Transportation Research Part B: Methodological 45 (10), 1619 - 1640.

URL http://dx.doi.org/10.1016/j.trb.2011.05.028 
Chorus, C., 2014. A generalized random regret minimization model. Transportation Research Part B: Methodological 68, $224-238$.

URL http://dx.doi.org/10.1016/j.trb.2014.06.009

Connors, R. D., Sumalee, A., 2009. A network equilibrium model with travellers' perception of stochastic travel times. Transportation Research Part B: Methodological 43, 614-624.

URL http://dx.doi.org/10.1016/j.trb.2008.12.002

Daganzo, C., Sheffi, Y., 1977. On stochastic models of traffic assignment. Transportation Science 11, $253-274$.

URL https://dx.doi.org/10.1287/trsc.11.3.253

Daganzo, C. F., 1982. Unconstrained extremal formulation of some transportation equilibrium problems. Transportation Science (16), 332-360. URL https ://dx.doi.org/10.1287/trsc.16.3.332

de Palma, A., Ben-Akiva, M., Brownstone, D., Holt, C., Magnac, T., McFadden, D., Moffatt, P., Picard, N., Train, K., Wakker, P., Walker, J., 2008. Risk, uncertainty and discrete choice models. Marketing Letters 19, 269-285.

URL https : //dx.doi.org/10.1007/s11002-008-9047-0

Fujii, s., Kitamura, R., 2004. Drivers' mental representation of travel time and departure time choice in uncertain traffic network conditions. Networks and Spatial Economics 4, 243-256.

URL https : //dx.doi.org/10.1023/B:NETS.0000039781.10517.3a

Gao, s., Frejinger, E., Ben-Akiva, M., 2010. Adaptive route choices in risky traffic networks: A prospect theory approach. Transportation Research Part C: Emerging Technologies 18, 727-740.

URL https://dx.doi.org/10.1016/j.trc.2009.08.001

Huang, H.-J., Lam, W. H. K., 2002. Modeling and solving the dynamic user equilibrium route and departure time choice problem in network with queues. Transportation Research Part B: Methodological 36, 253-273.

URL https: //dx.doi.org/10.1016/S0191-2615(00)00049-7

Jackson, W. B., Jucker, J. V., 1982. An empirical study of travel time variability and travel choice behavior. Transportation Science 16 (4), $460-475$. URL https://dx.doi.org/10.1287/trsc.16.4.460

Jiang, X., Ji, Y., Du, M., Deng, W., 2014. A study of drivers route choice behavior based on evolutionary game theory. Computational Intelligence and Neuroscience 2014.

Jou, R.-C., Kitamura, R., Weng, M.-C., Chen, C.-C., 2008. Dynamic commuter departure time choice under uncertainty. Transportation Research Part A: Policy and Practice 42, 774-783.

URL https://dx.doi.org/10.1016/j.tra.2008.01.017

Kahneman, D., Tversky, A., 1979. Prospect theory: An analysis of decision under risk. Econometrica 47 (2), $263-292$.

URL https://dx.doi .org/10.2307/1914185

Katsikopoulos, K. V., Duse-Anthony, Y., Fisher, D. L., Duffy, S. A., 2000. The framing of drivers' route choices when travel time information is provided under varying degrees of cognitive load. Human Factors: The Journal of the Human Factors and Ergonomics Society 42 (3), $470-481$. URL https : //dx.doi.org/10.1518/001872000779698088

Kemel, E., Paraschiv, C., 2013. Prospect theory for joint time and money consequences in risk and ambiguity. Transportation Research Part B 56, 81-95.

URL https://doi.org/10.1016/j.trb.2013.07.007

Lam, W. H., Shao, H., Sumalee, A., 2008. Modeling impacts of adverse weather conditions on a road network with uncertainties in demand and supply. Transportation Research Part B: Methodological 42 (10), 890 - 910.

URL https://dx.doi.org/10.1016/j.trb.2008.02.004

Leclercq, L., Becarie, C., 2012. A meso lighthill-whitham and richards model designed for network applications. In: Proceedings of the $91^{s t}$ Transportation Research Board Annual Meeting (TRB), 21-26 January, Washington (USA) [CDROM], Transportation Research Board, Washington.

Li, M., Huang, H.-J., 2016. A regret theory-based route choice model. Transportmetrica A: Transportation Science 13, $250-272$.

URL https: //dx.doi.org/10.1080/23249935.2016.1252445

Lo, H. K., Luo, X., Siu, B. W. Y., 2006. Degradable transport network: Travel time budget of travelers with heterogeneous risk aversion. Transportation Research Part B: Methodological 40 (9), 792-806.

URL https://dx.doi.org/10.1016/j.trb.2005.10.003

Mahmassani, H. S., Chang, G. L., 1987. On boundedly rational user equilibrium in transportation systems. Transportation Science $21,89-99$.

URL https: //dx.doi.org/10.1287/trsc.21.2.89

McFadden, D., 1978. Spatial Interaction Theory and Planning Models. MIT Press, Cambridge, MA, Ch. Modelling the choice of residential location, pp. 75-96.

Merchant, D. K., Nemhauser, G. L., 1978a. A model and an algorithm for the dynamic traffic assignment problems. Transportation Science 12 (3), 183-199.

URL https : //doi.org/10.1287/trsc.12.3.183

Merchant, D. K., Nemhauser, G. L., 1978b. Optimality conditions for a dynamic traffic assignment model. Transportation Science 12 (3), $200-207$. URL https://doi .org/10.1287/trsc.12.3.200

Nielsen, O. A., 1997. On the distributions of the stochastic components in sue (stochastic user equilibrium) traffic assignment models. In: Transportation planning methods: proceedings of seminar held at the European Transport Forum Annual Meeting, Brunel University, England 1-5 September 1997. pp. 77-93.

Ordóñez, F., Stier-Moses, N. E., 2010. Wardrop equilibria with risk-averse users. Transportation Science 44 (1), 63-86.

URL https ://dx.doi.org/10.1287/trsc.1090.0292

Prato, C. G., 2009. Route choice modelling: past, present and future research directions. Journal of Choice Modelling 2, 65-100.

URL https : //dx.doi .org/10.1016/S1755-5345(13)70005-8

Prelec, D., 1998. The probability weighting function. Econometrica 66 (3), 497-527.

URL https ://dx.doi.org/10.2307/2998573

Ramos, G. M., Daamen, W., Hoogendoorn, S., 2011. Expected utility theory, prospect theory, and regret theory compared for prediction of route 
choice behavior. Transportation Research Record 2230, 19-28.

URL https : //dx . doi .org/10.3141/2230-03

Ramos, G. M., Daamen, W., Hoogendoorn, S., 2013. Modelling travellers' heterogeneous route choice behaviour as prospect maximizers. The Journal of Choice Modelling 6, 17-33.

URL https://dx.doi.org/10.1016/j.jocm.2013.04.002

Sbayti, H., Lu, C.-C., Mahmassani, H. S., 2007. Efficient implementation of method of successive averages in simulation-based dynamic traffic assignment models for large-scale network applications. Transportation Research Record: Journal of the Transportation Research Board 2029, 22-30.

URL https : //dx.doi.org/10.3141/2029-03

Senbil, M., Kitamura, R., 2004. Reference points in commuter departure time choice: A prospect theoretic test of alternative decision frames. Journal of Intelligent Transportation Systems 8, 19-31.

URL https : //dx.doi.org/10.1080/15472450490437726

Shao, H., Lam, W., Meng, Q., Tam, M., 2006. Demand-driven traffic assignment problem based on travel time reliability. Transportation Research Record 1985, 220-230. URL https ://dx.doi.org/10.3141/1985-24

Shao, H., Lam, W. H. K., Tam, M. L., Sep 2006. A reliability-based stochastic traffic assignment model for network with multiple user classes under uncertainty in demand. Networks and Spatial Economics 6 (3), 173-204.

URL https : //dx.doi .org/10.1007/s11067-006-9279-6

Sheffi, Y., 1985. Urban Transportation networks: Equilibrium Analysis with Mathematical Programming Methods. Prentice Hall Inc., United States of America, Ch. 10 and 11.

Simon, H. A., 1957. A behavioral model of rational choice. Wiley, New York.

Small, K. A., 1982. The scheduling of consumer activities: Work trips. The American Economic Review 72 (3), $467-479$. URL http: //www . jstor.org/stable/1831545

Sumalee, A., Connors, R. D., Luathep, P., 2009. Network equilibrium under cumulative prospect theory and endogenous stochastic demand and supply. Transportation and Traffic Theory 2009: Golden Jubilee, 19-38. URL https://dx.doi .org/10.1007\%2F978-1-4419-0820-9_2

Szeto, W. Y., Lo, H. K., 2006. Dynamic traffic assignment: properties and extensions. Transportmetrica 2 (1), 31-52. URL https://dx.doi.org/10.1080/18128600608685654

Tversky, A., Kahneman, D., 1992. Advances in prospect theory: Cumulative representation of uncertainty. Journal of Risk and Uncertainty 5 (4), 297-323.

URL https : //dx.doi.org/10.1007/978-3-319-20451-2_24

Viti, F., Bogers, E., Hoogendoorn, S., 2005. Day-to-day learning under uncertainty with information provision: model and data analysis. In: Proceedings of the $16^{\text {th }}$ International Symposium of Transportation and Traffic Theory, College Park, MD (USA).

Wardrop, J. G., 1952. Some theoretical aspects of road traffic research. Institution of Civil Engineering 1, 325-362. URL https ://dx.doi.org/10.1680/ipeds.1952.11259

Watling, D., 2006. User equilibrium traffic network assignment with stochastic travel times and late arrival penalty. European Journal of Operational Research 175 (3), 1539-1556. URL https://dx.doi.org/10.1016/j.ejor.2005.02.039

Xu, H., Louc, Y., Yinb, Y., Zhoua, J., 2011. A prospect-based user equilibrium model with endogenous reference points and its application in congestion pricing. Transportation Research Part B: Methodological 45 (2), 311-328. URL https://dx.doi.org/10.1016/j.trb.2010.09.003

Yang, J., Jiang, G., 2014. Development of an enhanced route choice model based on cumulative prospect theory. Transportation Research Part C 47, 168-178.

URL https://dx.doi.org/10.1016/j.trc.2014.06.009

Zhou, L., Zhong, S., Ma, S., Jia, N., 2014. Prospect theory based estimation of driver's risk attitudes in route choice behaviors. Accident Analysis and Prevention 73, 1-11. URL https: //dx.doi.org/10.1016/j.aap.2014.08.004

Zhu, S., 2011. The Roads Taken: Theory and Evidence on Route Choice in the Wake of the I-35w Mississippi River Bridge Collapse and Reconstruction. PhD thesis. University of Minnesota. 